\title{
EL NECESARIO AJUSTE DE LA ASIGNACIÓN DEL RIESGO DE SOBREENDEUDAMIENTO EN LA REGULACIÓN DE LAS TARJETAS DE CRÉDITO: DESDE UN SISTEMA BASADO EN LOS DEBERES DE INFORMACIÓN A UN MODELO DE CORRESPONSABILIDAD
}

[The necessary adjustment of the allocation of the risk of over-indebtedness in the regulation of credit cards: from a system based in the duties of information to a model of joint responsibility]

\section{Juan Luis Goldenberg Serrano*}

\begin{abstract}
RESUMEN
El énfasis del tratamiento normativo de las tarjetas de crédito en el deber de información desconoce importantes aspectos conductuales y asume que el consumidor puede proyectar adecuadamente sus ingresos y gastos para ponderar los efectos de su elección en su economía personal. Tal modelo potencia el riesgo de sobreendeudamiento, lo que afecta al deudor y grava todo el sistema económico. Para promover una mejor respuesta, se pretende explorar la posibilidad de construir un sistema de "préstamos responsables", y, como primer paso, reconocer un deber de
\end{abstract}

\begin{abstract}
The emphasis of the legal framework of credit cards regarding the information duties ignores important behavioral aspects and assumes that the consumer can adequately project his income and expenses to weight the effects of such election in his personal economy. Such model increases the risk of overindebtedness, affecting the debtor and burdening the entire economic system. To promote a better response, I intend to explore the relevance of building a system of "responsible loans", and, as a first step, recognize a duty of advice all
\end{abstract}

RECIBIDO el 30 de octubre y ACEPTADO el 20 de diciembre

* Doctor en Derecho, Universidad de Salamanca. Profesor de Derecho Civil de la Facultad de Derecho de la Pontificia Universidad Católica de Chile. Dirección postal: Av. Libertador Bernardo O’Higgins N. ${ }^{\circ}$ 340, Santiago. Correo electrónico: jgoldenb@uc.cl. Quiero agradecer los comentarios efectuados por la profesora Francisca Barrientos Camus a una versión preliminar del presente trabajo. 
asesoría que se despliegue en la fase precontractual y durante toda la vigencia del contrato.

\section{Palabras clave}

Tarjetas de crédito - protección del consumidor - información - asesoría, sobreendeudamiento. through the pre-contractual phase and the term of the contract.

KEY WORDS

Credit cards - consumer protection - information - advise - overindebtedness.

\section{INTRODUCCIÓN}

Las tarjetas de crédito constituyen un instrumento ampliamente extendido en nuestro entorno, haciendo eco de las tendencias generales del comercio que han afirmado que se tratan estas de "los medios más difundidos y seguros utilizados como medio de pago de las obligaciones de dinero"1. Su nivel de penetración en Chile, como también el monto total de las operaciones realizadas a su amparo, permiten señalar que, en conjunto con los créditos hipotecarios, constituyen una de las formas más habituales de acceso al crédito por parte de la población. Esta propagación ha sido alentada por el desarrollo tecnológico, como también por las políticas de inclusión financiera impulsada por nuestras autoridades ${ }^{2}$.

$\mathrm{Al}$ efecto, la Asociación de Bancos e Instituciones Financieras nos informa que un 23\% de los hogares utiliza tarjetas de crédito bancarias, cifra que se eleva hasta un $52 \%$ en los hogares de ingresos superiores. Asimismo, se observa un uso bastante más intenso de las tarjetas de crédito no bancarias, que, en promedio llega a un 53\% de los hogares ${ }^{3}$. Por su parte, las estadísticas de la Superintendencia de Bancos e Institu-

${ }^{1}$ Gete-Alonso - Calera, María del Carmen, Las tarjetas de crédito (Madrid, Marcial Pons, 1997), pp. 11 y 12.

${ }^{2}$ La inclusión financiera advierte que el acceso al crédito puede ser utilizado como una herramienta para la superación de la pobreza y el incremento del bienestar social. De ahí la propuesta que el acceso al crédito sea reconocido como un derecho humano (Hudon, Marek, Should Access to credit be a right, en Journal of Business Ethics 84 (2009), pp. 17 - 28), aunque se hayan señalado los dilemas morales implícitos en esta idea (WHITE, Alan M., Credit and human welfare: Lessons from microcredit in developing nations, en Washington and Lee Law Review 69 (2012) 2, pp. 1093-1140). En Chile, en el año 2014 se creó una "Comisión Asesora para la Inclusión Financiera” (Decreto N. ${ }^{\circ}$ 954, de 2014, del Ministerio de Hacienda), al tiempo que la SBIF también la ha destacado como uno de sus pilares estratégicos (SBIF, Informe de inclusión financiera en Chile 2016, 2016 [visible en internet: www.sbif.cl].

\footnotetext{
${ }^{3} \mathrm{ABIF}$, Informe N. ${ }^{\circ} 72$, de 28 de marzo de 2016 [visible en internet: www.abif.cl].
} 
ciones Financieras ("SBIF") 4 también demuestran un considerable nivel de acceso a las tarjetas como medio de financiamiento. Se destaca que un $34 \%$ de la población adulta tendría tarjetas de crédito bancarias y un $31 \%$, tarjetas de crédito no bancarias. Conforme al Informe Financiero sobre Tarjetas de Crédito de la SBIF a julio de $2017^{5}$, se registraba un total de 12.860.777 tarjetas de crédito, distribuyéndose en 10.575 .332 en calidad de titular y 2.285 .445 como adicionales ${ }^{6}$. En cuanto al tipo de operaciones y su monto, se registraron 835.028 avances en efectivo (por un monto de 183.912.996.605 pesos); 26.061 .772 operaciones de compras (por un monto de 1.235.429.527.021 pesos); y 3.917.892 cargos por servicios contratados (por un monto de 76.432 .849 .393 pesos). Así, se registraron, en total, 30.814 .692 operaciones por un monto total de 1.495.775.373.019 pesos.

Todo ello se enmarca en la manera en que ha evolucionado nuestra forma de consumir, y que se integra en la denominada "sociedad de consumo". Esta, como advierte Burton, se construye sobre la base de tres pilares fundamentales: la "producción en masa", el "marketing en masa" y el "financiamiento en masa", dando cuenta este último de las lógicas de la necesaria expansión del crédito como soporte del modelo económico? Así, en términos globales, los niveles de endeudamiento han presentado un alza sostenida a partir de la década de los setenta del siglo XX, en virtud de una facilitación de acceso al mercado de crédito, como un medio para lograr un incremento del consumo. Con ello, se ha pretendido conseguir un impacto en la situación social y financiera de las economías domésticas dado el crecimiento positivo de los productos brutos y la consecuente alza en los índices de empleo ${ }^{8}$.

En este contexto, las tarjetas de crédito se ofrecen como una herramien-

${ }^{4}$ SBIF, cit. (n. 2).

${ }^{5}$ Disponible en http://www.sbif.cl/sbifweb/servlet/InfoFinanciera?indice=4. 1\&idCategoria $=564 \&$ tipocont $=568$.

${ }^{6}$ Tal situación da cuenta de una evolución al alza, sostenida a partir de 1991, en que el total era sólo de 890.481 tarjetas, que en el año 2000 ya llegaban a 2.494 .464 y en el año 2010 a 4.887.405. Cabe destacar que, si bien la información pública disponible está dada a partir del año 1991, Prado Puga, Arturo, Algunas consideraciones sobre la tarjeta de crédito, en Gaceta Jurídica 131 (1991), pp. 7-16, y MELLA CÁCERES, Rodrigo y Larraín Fierro, Álvaro, Derecho bancario (Santiago, Thomson Reuters, La Ley, 2016), p. 163, nos informan que las tarjetas de crédito fueron introducidas en Chile en el año 1979 por parte de Diners Club. Estos últimos autores también efectúan una reseña sobre la evolución histórica del instrumento (pp. 164-165).

7 Burton, Dawn, Credit and consumer society (Routledge, Nueva York, 2008), p. 29.

${ }^{8}$ Bouyon, Sylvain y Muscemi, Roberto, Las dos dimensiones del sobreendeudamiento: protección del consumidor y estabilidad financiera en la Unión Europea, en La prevención del 
ta aparentemente simplificada para el consumidor puesto que, liberado de las dificultades que implicaba la necesidad de ahorro previo, se configura la posibilidad de tener un acceso expedito al crédito y a la fijación de sus condiciones de pago 9 . Desde su punto de vista, este instrumento le permite anticipar la adquisición de un vasto número de bienes y servicios difiriendo el pago del precio (incluso, fraccionándolo en cuotas), pero no mediante un acuerdo particular con el proveedor, sino por medio de un crédito concedido por el emisor de la tarjeta. No obstante, la utilización de este dispositivo envuelve ciertos riesgos para el consumidor en la medida en la que se trata de una forma de incentivar el consumo sin una delimitación específica del uso eficiente (o no) a la que puede dar lugar, devengando intereses y justificando el cobro de comisiones por su carácter rotativo. Pero, adicionalmente a ello, su uso puede dar cabida a fenómenos de sobreendeudamiento ${ }^{10}$, que pueden incidir en la vida de los consumidores como una causa de marginación social ${ }^{11}$, y, en el sistema en general, como un factor de la disminución de la demanda interna y la generación de un espiral que puede impactar, incluso, en la estabilidad del sistema financiero ${ }^{12}$. Especialmente a partir de la denominada crisis subprime, se constató a nivel mundial que la falta de respuestas concretas al sobreendeudamiento de los particulares incrementó el número de personas que, en lugar de contribuir a la sociedad, fueron forzadas a depender de ella ${ }^{13} ; \mathrm{y}$, al tiempo en que el incumplimiento masivo provocó el debilitamiento de las entidades financieras, debió incluso recurrirse a instancias de conversión de la "deuda privada" en deuda pública", haciendo que los Estados terminasen socavando su propia solvencia ${ }^{14}$. Estas consecuencias desencadenaron

sobreendeudamiento privado. Hacia un préstamo y consumo responsables (Cizur Menor, Thomson Reuters Aranzadi, 2017), pp. 99 y 100.

9 Saint-Alary-Houin, Corinne, El tratamiento de las dificultades financieras de los particulares en Francia, en CuenA, Matilde - Colino, José Luis (coordinadores), Endeudamiento del consumidor e insolvencia familiar (Cizur Menor, Thomson Reuters / Civitas, 2009), p. 401.

${ }_{10}$ Sobre la indicación de las tarjetas de crédito como una de las principales responsables del endeudamiento de los consumidores se pronuncian MeLLa CÁceres, Rodrigo y Larraín Fierro, Álvaro, cit. (n. 6), p. 172.

11 Vid. Dictamen del Comité Económico y Social Europeo (2008/C 44/19).

12 Pulgar Esquerra, Juana, El presupuesto objetivo de la prevención y tratamiento de las crisis económicas de los consumidores, en CuENA, Matilde - Colino, José Luis (coordinadores), Endeudamiento del consumidor e insolvencia familiar (Cizur Menor, Thomson Reuters / Civitas, 2009), p. 64.

${ }_{13}$ AtAmer, Yesim M., Duty of responsible lending: should the European Union take action?, en Financial services, financial crisis and general European contract law (Alphen aan den Rijn, Wolters Kluwer, 2011), p. 186.

${ }^{14}$ Raga GIL, José T., Sobreendeudamiento privado y crisis financiera, en La prevención del 
fenómenos de aceleración de la pobreza, incrementados por los planes de austeridad que debieron llevar adelante las economías afectadas.

Para comprender este fenómeno pretendo comprobar que las tarjetas de crédito constituyen un mecanismo de acceso al crédito que revela variadas dificultades técnicas, no sólo en lo referente a la formulación de una teoría que describa todos los aspectos relevantes de su naturaleza jurídica, sino especialmente por las complejas valoraciones financieras que se desprenden de su contratación, de su utilización y de la elección de su forma de pago. Si bien dichos aspectos han sido considerados por los reguladores nacionales, sea por vía legal o reglamentaria, se ha puesto énfasis en la protección del consumidor ("tarjetahabientes"15) por medio del acceso a un amplísimo campo de información que le debe ser entregada durante todo el íter contractual. Dicho de otro modo, la normativa asume que a partir de la mentada técnica el consumidor será capaz de proyectar racionalmente las consecuencias económicas de su decisión, asunción que, a mi juicio, envuelve el riesgo de que, cumplidos los deberes de información por parte del proveedor del crédito, no quepa considerar otras medidas de resguardo para el deudor, en particular, ante los riesgos de sobreendeudamiento ${ }^{16}$. Por lo anterior, el objetivo de este trabajo consiste en comprobar que este diseño regulatorio resulta del todo insuficiente, al menos en lo que se refiere a la asignación del mentado riesgo de sobreendeudamiento; pero que ello no impide evidenciar ciertos elementos del ordenamiento nacional que permiten configurar una lógica de "préstamos responsables",

sobreendeudamiento privado. Hacia un préstamo y consumo responsables (Cizur Menor, Thomson Reuters Aranzadi, 2017), p. 59.

${ }^{15}$ Denominación utilizada en la Ley N. ${ }^{\circ} 20.009$, de 2005.

${ }^{16}$ El sobreendeudamiento expresa una situación patrimonial crítica de una persona natural, pero el concepto es aún impreciso en la definición de sus contornos económicos. De ello se derivan las dificultades para la configuración de su contenido jurídico a modo del establecimiento de sus requisitos y formas de acreditación (Beltrán SÁnchez, Emilio, El concurso de acreedores del consumidor, en Cuena, Matilde - Colino, José Luis (coordinadores), Endeudamiento del consumidor e insolvencia familiar (Cizur Menor, Thomson Reuters / Civitas, 2009), p. 119). En el Dictamen del Comité Económico y Social Europeo (2008/C 44/19), la aproximación a la noción se efectúa del siguiente modo: "Hablar de endeudamiento excesivo o de sobreendeudamiento es hacer referencia a situaciones en las que el deudor se ve en la imposibilidad, de forma duradera, de pagar el conjunto de sus deudas, o expuesto a una amenaza seria de no poder hacerles frente en el momento en que sean exigibles". En el contexto nacional, aunque eminentemente en clave concursal, han abordado el tema Pérez Ragone, Álvaro - Martínez Benavides, Patricio, Del sobreendeudamiento a la insolvencia: fases de crisis del deudor desde el derecho comparado europeo, en Revista Chilena de Derecho 42 (2015) 1, pp. 93 - 121; y Ruz Lártiga, Gonzalo, Nuevo Derecho concursal chileno (Santiago,Thomson Reuters, 2017), I, pp. 490 - 495. 
en los que el concedente del crédito debe advertir la existencia de dichos riesgos de manera más específica al consumidor, guiándolo a modo de asesorías pormenorizadas, todo observado desde la lógica de una eventual corresponsabilidad en el endeudamiento excesivo. Para los efectos de analizar lo anterior, contextualizaré el problema a partir de la identificación del marco normativo de las tarjetas de crédito (II), a fin de destacar los alcances de la preocupación puesta en el ofrecimiento de información al tarjetahabiente. Luego, me referiré a los problemas que esta construcción plantea, tanto en términos generales en referencia a cualquier relación de consumo, como en particular respecto a las tarjetas de crédito (III). Sin embargo, como no deseo dejar el análisis en la mera enunciación de los problemas, por lo que propongo un primer paso para la construcción de un sistema de "préstamos responsables" por medio del reconocimiento de un deber de asesoramiento por parte del concedente del crédito que se despliegue durante todo el íter contractual, centrado, en este punto, en la identificación de los riesgos de sobreendeudamiento (IV).

\section{Marco normativo de las tarjetas de Crédito y EL ÉNFASIS EN LA CREACIÓN DE UN MODELO BASADO EN LA \\ INFORMACIÓN DISPONIBLE PARA EL CONSUMIDOR}

\section{Una breve referencia al concepto y a la naturaleza de las tarjetas de crédito}

Las normas de la SBIF y del Banco Central ("BC") ${ }^{17}$, como asimismo el artículo 3.1. del Decreto N. ${ }^{\circ} 44$, de 2012, del Ministerio de Economía, que aprueba el reglamento sobre información al consumidor de tarjetas de crédito bancarias y no bancarias, definen estas últimas como "cualquier instrumento que permita a su titular o usuario disponer de un crédito otorgado por el emisor, utilizable en la adquisición de bienes o en el pago de servicios prestados o vendidos por entidades afiliadas con el correspondiente emisor u operador, en virtud de convenios celebrados con éstas que importen aceptar el citado instrumento como medio de pago, sin perjuicio de las demás prestaciones complementarias que puedan otorgarse al titular o usuario".

En esta definición se destacan a los actores que participan en la operatoria de esta clase de tarjetas (titulares, usuarios, emisores, operadores y entidades afiliadas que proporcionen bienes o servicios ${ }^{18}$, al tiempo en

${ }^{17}$ Circular de Emisores y Operadores de Tarjetas de Crédito N. ${ }^{\circ}$ 35, de 13 de mayo de 2010; Capítulo 8-3 de la Recopilación Actualizada de Normas de la SBIF; Capítulo III.J.1 del Compendio de Normas Financieras del BC.

${ }^{18}$ Sobre el carácter tripartito de la operación, vid. Prado Puga, Arturo, cit. (n. 6) y Sandoval López, Ricardo, Tarjeta de crédito bancaria (Santiago, Editorial Jurídica 
que se da cuenta de su objetivo: el otorgamiento de un crédito por parte del emisor para ser utilizado por el tarjetahabiente como medio de pago frente a una entidad afiliada. Esto supone una disposición de crédito que no por ello se ajusta perfectamente a la noción de operación de crédito de dinero contenida en el artículo $1^{\circ}$ de la Ley N. ${ }^{\circ} 18.010$, puesto que no implica el compromiso de entregar una cantidad de dinero directamente al tarjetahabiente (función de crédito), sino ofrecer un reemplazo en el obligado al pago con la entidad afiliada sobre la base del uso efectuado por su titular (función de pago) ${ }^{19}$.

Sin perjuicio de lo anterior, la misma ley ignora la dificultad de encuadre a efectos de disponer la forma de cómputo de la tasa máxima convencional aplicable a los créditos originados debido a la utilización de las tarjetas de crédito, entendiendo que, bajo ellas, opera una línea de crédito pactada entre el titular y el emisor, sea de modo rotativo o refundido (artículo $6^{\circ}$ ter de la Ley N. $\left.{ }^{\circ} 18.010\right)^{20}$. Tal sustrato también se colige de varias normas del Decreto N. ${ }^{\circ} 44$, de $2012^{21}$, aunque se presentaba de manera más clara en versiones anteriores del Compendio de Normas Financieras del BC ${ }^{22}$ al tiempo en que la emisión de las tarjetas de crédito se sujetaba de modo expreso a una apertura de crédito. Ya situados en torno a la naturaleza jurídica de la tarjeta de crédito ${ }^{23}$, esto implica que ella comporta un dispositivo instrumental para efectuar disposiciones al alero de la mentada apertura y, en suma, permite apreciar los términos de la relación jurídica entre dos de los actores: el tarjetahabiente y el emisor. Cabe concluir que no es indispensable que el dinero sea entregado directamente al deudor, como parecía implícito en la definición legal de las operaciones de crédito

de Chile, 1991), pp. 38-40. Sin perjuicio de lo anterior, cabe tener presente que las tarjetas de crédito pueden tener un carácter bipartito, cuando son emitidas, por ejemplo, por la propia entidad comercial, diferenciando las denominadas "two-party cards" de las "three-party cards" (Durkin, Thomas A. - Elliehausen, Gregory - STATEN, Michael E. - ZYwICKI, Todd J., Consumer credit and the American economy (Nueva York, Oxford University Press, 2014), p. 290). Para los efectos de este estudio nos referimos preferentemente a este último tipo dado que, a nuestro juicio, es aquí donde el consumidor puede tener mayores dificultades para la delimitación de los riesgos en el uso de la tarjeta.

${ }^{19}$ Sobre la disociación entre estos dos aspectos, puede consultarse la Sentencia de la Corte de Apelaciones de Santiago de 27 de enero de 2016, rol 1585-2015, caratulada "Servicio Nacional del Consumidor con Sony Chile Limitada".

${ }^{20}$ Incorporado por la Ley N. ${ }^{\circ} 20.715$, de 2013.

${ }^{21}$ Artículos 3.8, 3.14, 3.15, 3.16, 3.22, 3.26, 3.29, 3.26, 3.56, 4, 11.1, 11.2, 11.8, 11.9, 19, 23, 29, 30, 31 y 38 del Decreto N. ${ }^{\circ} 44$, de 2012.

${ }^{22}$ Capítulo III I-1 del Compendio de Normas Financieras del BC.

${ }^{23}$ Sobre las dificultades para concretar la naturaleza jurídica de una relación triangular como la que ofrecen las tarjetas de crédito, Prado Puga, Arturo, cit. (n. 6). 
de dinero ${ }^{24}$, como tampoco que ella suponga una entrega física del dinero, bastando la asunción de la obligación de pago por parte del emisor respecto a los comercios afiliados a través de un complejo sistema de registro de operaciones electrónicas ${ }^{25}$.

Pues bien, la inclusión del crédito derivado del uso de las tarjetas en el marco de la Ley N. ${ }^{\circ} 18.010$ es relevante para este discurso por dos aspectos adicionales: en primer lugar, la posibilidad de anatocismo, en los términos en que éste aparece admitido en su artículo $9^{\circ}$, proyectando un aumento ostensible de la deuda durante su horizonte de pago, el que no necesariamente es reconocido por el consumidor al tiempo de hacer uso del instrumento; y, luego, porque en la evolución del tratamiento de las operaciones de crédito de dinero se ha observado una creciente incidencia de la lógica de protección de los derechos de los consumidores, bastante más apreciable a partir de las modificaciones incorporadas por la Ley N. ${ }^{\circ}$ 20.715. Esto permite su identificación como producto financiero y su coordinación con las reglas de la Ley N. 19.496 (“LPDC”), especialmente si se considera que el contrato de emisión de la tarjeta de crédito, que dará cuenta de los términos jurídicos y económicos derivados de su uso, se estructurará bajo la fórmula de un contrato por adhesión, activando los diversos mecanismos de tutela previstos en la citada normativa. Por el momento, sólo me interesa indagar en los deberes de información formulados por el ordenamiento jurídico chileno, porque, como veremos, estos constituyen el núcleo de la protección ideada para el consumidor en el tratamiento normativo de las tarjetas de crédito.

\section{El marco jurídico aplicable a los deberes de información a favor de los tarjeta-} babientes

a) Comentarios generales sobre la consagración del deber de información. La imposición al emisor de un espectro pormenorizado de la información a ser entregada al consumidor constituiría una solución que se reforzaría por consideraciones de política económica que, como indican de la Maza y

${ }^{24}$ Respecto al encuadre de la línea de crédito en el concepto de las operaciones de crédito de dinero, vid. Guzmán Brito, Alejandro, El concepto de crédito en el Derecho chileno, en Revista de Derecho (Universidad Católica del Norte), 21 (2014) 2, pp. 441 y 442.

${ }^{25}$ Sección I.1 del Capítulo III.J.1 del Compendio de Normas Financieras del BC. Sobre el particular, Prado Puga (1991) entiende que es el pago con subrogación el que mejor se aviene a la figura, aplicando la norma del artículo $1601 \mathrm{~N} .^{\circ} 5 \mathrm{CC}$, lo que, sin embargo, no permite entender las razones por las cuales el emisor puede cobrar una comisión a la entidad afiliada por el uso del sistema. 
Andrade, son más ajustadas a las economías de libre mercado ${ }^{26}$. En virtud de ello puede observarse que en todos estos mecanismos de información no se dispone únicamente de una tutela a los consumidores, sino que se articula también en su proyección al mercado en general, desde la vereda de la protección de la competencia ${ }^{27}$. De tal suerte, está implícita en esta forma de regulación la posibilidad de que, por medio de una comparación basada en una información uniforme y veraz ${ }^{28}$, el consumidor transite hacia fuentes de financiamiento más baratas y convenientes.

En general, nuestra doctrina ha entendido que el establecimiento de deberes de información tiene diversas justificaciones ${ }^{29}$. La más evidente se encuentra en los problemas de asimetría de información que justifican el tratamiento especial del derecho del consumo, basado en la posición de desigualdad que existiría entre consumidores y proveedores ${ }^{30}$. Por ello, su consagración supone que el costo de la información requerida para la satisfacción del deber es menor que los beneficios esperados por

${ }^{26}$ De la Maza Gazmuri, Iñ̃igo, El suministro de información como técnica de protección de los consumidores: los deberes precontractuales de información, en Revista de Derecho (Universidad Católica del Norte), 17 (2010) 2, p. 31, y Andrade Ramírez, Víctor Miguel, La protección al consumidor de tarjetas de crédito: ¿ son suficientes los deberes de información?, 2013 [visible en internet: https://papers.ssrn.com/sol3/papers2.cfm?abstract id=2349131], p. 4.

27 Álvarez Vega, María Isabel, La protección jurídica del consumidor sobreendeudado e insolvente (Cizur Menor, Thomson Reuters/Civitas, 2010), p. 169.

${ }^{28}$ Finalidad que se observa, por ejemplo, de la información relativa al costo total del producto o servicio, configurada como la carga anual equivalente tratada en el artículo 17 G LPDC. Sobre el punto, Baquero Herrera, Mauricio - Caballero Germain, Guillermo, Artículo 17 G, en De la Maza, Íñigo - Pizarro, Carlos (directores) - Barrientos, Francisca (coordinadora), La protección de los derechos de los consumidores. Comentarios a la Ley de protección a los derechos de los consumidores (Santiago, Thomson Reuters, 2013), pp. 449-467.

${ }^{29}$ Para un análisis general de la materia en el marco de los servicios bancarios y de inversión, vid. HeRnÁndez PAulsen, Gabriel, La obligación precontractual de las entidades de crédito de informar al cliente en los servicios bancarios y de inversión (Madrid, Marcial Pons, 2014), pp. 80 -111.

${ }^{30}$ De la Maza, Íñigo, cit. (n. 26), p. 26; De la Maza Gazmuri, Íñigo, Artículo $1^{\circ}$ N. $^{\circ} 3$, en De la Maza, Íñigo - Pizarro, Carlos (directores) - Barrientos, Francisca (coordinadora), La protección de los derechos de los consumidores. Comentarios a la Ley de protección a los derechos de los consumidores (Santiago, Thomson Reuters, 2013), p. 24; Barrientos Zamorano, Marcelo, Artículo $3^{\circ}$ B), en De la Maza, Íñigo - Pizarro, Carlos (directores) - BARRIENTOS, Francisca (coordinadora), La protección de los derechos de los consumidores. Comentarios a la Ley de protección a los derechos de los consumidores (Santiago, Thomson Reuters, 2013), pp. 97- 99; Andrade Ramírez, Víctor, cit. (n. 26), p. 7; Rostión, Ignacio, SERNAC Financiero: nuevos deberes de información y responsabilidad civil, en Revista de Derecho (Universidad Católica del Norte), 21 (2014) 1, p. 427. 
su generación y transmisión ${ }^{31}$, cuestión que no sólo repara en la posición particular del consumidor, sino en los estándares generales de transparencia del mercado para alentar la competencia entre los actores económicos.

Ya en términos jurídicos, su reconocimiento se derivaría del principio de buena $\mathrm{fe}^{32}$, entendiendo que ésta se incardina como un deber de conducta genérico que se despliega incluso en la fase precontractual, en términos de construir confianza y cooperación entre las partes ${ }^{33}$. Por ello, suele establecerse como un contrapunto del deber del consumidor de informarse de forma responsable de las condiciones de la contratación, aunque éste se presente de manera difusa (o lírica ${ }^{34}$ ), dado que se acepta que éste debe construirse desde la lógica de la asimetría informativa antes citada que se asume pesar sobre sus hombros ${ }^{35}$. Y, aún más lejano, se ofrecería también como un instrumento para el cumplimiento del derecho asignado al consumidor para ser educado para el consumo responsable ${ }^{36}$. Ello, aun cuando esta obligación pueda ser caracterizada como "de medios" ${ }^{37}$, en tanto no puede exigirse al proveedor que el consumidor comprenda todos los términos de la relación, bastando un estándar de claridad y sencillez ${ }^{38}$.

${ }^{31}$ Barrientos Zamorano, Marcelo, cit. (n. 30), p. 96.

32 Especialmente, Fernández Acevedo, Fernando, Artículo $17 A$, en De la Maza, Iñigo - Pizarro, Carlos (directores) - Barrientos, Francisca (coordinadora), La protección de los derechos de los consumidores. Comentarios a la Ley de protección a los derechos de los consumidores (Santiago, Thomson Reuters, 2013), pp. 365 y 366, y BARRIENTos Zamorano, Marcelo, cit. (n. 30), p. 97. Este razonamiento fue considerado en la Sentencia de la Corte de Apelaciones de Copiapó de 11 de marzo de 2016, rol 4-2016, caratulada "Oscar Clavijo Guevara con Banco Estado".

${ }_{33}$ Rostión, Ignacio, cit. (n. 30), p. 428.

${ }^{34}$ Rodríguez Grez, Pablo, Derecho del consumidor. Estudio crítico (Santiago, Thomson Reuters/La Ley, 2015), p. 16.

${ }^{35}$ Incluso, De LA MAZA, Íñigo, cit. (n. 26), p. 37 niega su carácter de deber porque su infracción no genera responsabilidad, aun cuando BARrientos ZAMORANO, Marcelo, cit. (n. 30), p. 98, aprecie una unión indisoluble entre el derecho de ser informado y el deber de informarse, en los términos expresados en el artículo $3^{\circ} \mathrm{B}$ ) LPDC.

${ }^{36}$ Sandoval López, Ricardo, Derecho del consumidor (Santiago, Editorial Jurídica de Chile, 2004), p. 141. Ahora bien, el derecho a la educación para el consumo responsable no parece articulado de forma adecuada en los términos propios de la LPDC, como apunta Rodríguez Grez, Pablo, cit. (n. 34), p. 19, aunque pueda comprenderse como un lineamiento programático de sus disposiciones a efectos de que los diversos actores participen en iniciativas que faciliten un consumo ajustado a los requerimientos y posibilidades financieras del consumidor.

${ }^{37}$ Aimone Gibson, Enrique, Protección de derechos del consumidor (Santiago, Legalpublishing/Thomson Reuters, 2013), p. 8.

38 En nuestro ordenamiento, un deber general en esta materia se contempla en el artículo 3, letra b) de la LPDC., especialmente al referirse a su veracidad y 
b) Normativa aplicable a las tarjetas de crédito. Sobre estas bases, el ordenamiento nacional ha construido un sistema general y particular de protección del tarjetahabiente por medio de reglas configurativas del deber de información por parte del emisor, aunque por medio de una dispersión normativa que resulta poco clarificadora y, a la vez, compleja en la fijación de su contenido ${ }^{39}$. No es mi interés descender al detalle de todas dichas reglas aplicables, sino dar cuenta de la forma en la que el mencionado deber de información se establece conforme a la lógica tutelar que gobierna nuestro Derecho de consumo.

aa) La LPDC y el Decreto N. ${ }^{\circ} 44$, del Ministerio de Economía. Tratándose de un producto financiero, la información a ser entregada por el emisor se enmarca en el cuadro protector dispuesto en la LPDC. Como apunta Andrade, el espíritu de esta normativa manifiesta un tratamiento que supera las regulaciones destinadas a la reducción de los riesgos de las instituciones financieras y sus depositantes, situando la protección del consumidor en el centro de una nueva política pública en materia financiera ${ }^{40}$, en especial a partir de la Ley N. ${ }^{\circ} 20.555$. Esta reforma optó por la particularización de ciertos deberes a favor del denominado "consumidor financiero", sin que por ello no resulten cubiertos por los derechos esenciales conferidos de modo genérico a todos los consumidores ${ }^{41}$. Ello se sustentaría en la evidencia de que los productos y servicios financieros "suelen tener una complejidad bastante mayor a la que se ve expuesto el consumidor en otras fórmulas contractuales" ${ }^{42}$, al tiempo en que se evidencia una mayor sofisticación de los mercados financieros, como ha ocurrido, por ejemplo, mediante la creación de las tarjetas de crédito ${ }^{43}$. Así, en el aspecto que nos

completitud, materias que son reconducidas por DE LA MAZA, Íñigo, cit. (n. 26), p. 44, a la necesidad de que la información también sea comprensible, esto es, "que su contenido resulte intelectualmente accesible a un consumidor medio sin que deba realizar un esfuerzo intelectual extraordinario o requiere de la asistencia de terceros o procurarse de información adicional", exigencia que se desprende de lo dispuesto en el artículo 32 LPDC. en relación con la información básica comercial.

39 Mella Cáceres, Rodrigo - Larraín Fierro, Álvaro, cit. (n. 6), p. 163.

${ }^{40}$ Andrade Ramírez, Víctor, cit. (n. 26), p. 3.

${ }^{41}$ San Martín Neira, Lilian, Artículo $3^{\circ}$ inciso $2^{\circ}$, en De la Maza, Íñigo - PizaRRO, Carlos (directores) - BARRIENTOS, Francisca (coordinadora), La protección de los derechos de los consumidores. Comentarios a la Ley de protección a los derechos de los consumidores (Santiago, Thomson Reuters, 2013), p. 143.

${ }^{42}$ Goldenberg Serrano, Juan Luis, Artículo 17 D, en De la Maza, Íñigo y PIZARRO, Carlos (directores) y BARRIEnTOS, Francisca (coordinadora), La protección de los derechos de los consumidores. Comentarios a la Ley de protección a los derechos de los consumidores (Santiago, Thomson Reuters, 2013), p. 422.

${ }^{43}$ Respecto a las complejidades del contrato de emisión de tarjeta de crédito, vid. 
interesa, las medidas de protección se construyen sobre la base de la información que debe recibir el consumidor, intensificadas y particularizadas en los términos dispuestos en el inciso segundo del artículo $3^{\circ} \mathrm{LPDC}^{44}$, y detallados a partir del artículo 17 B LPDC.

De tal modo, se asigna un derecho básico al consumidor de esta clase de productos en referencia a su costo total, incluyendo la "carga anual equivalente" y el conocimiento de la liquidación total del crédito a su solo requerimiento (artículo 3 II LPDC). Los términos contractuales desglosados de forma extensa en el artículo 17 B LPDC también pretenden "promover la simplicidad y transparencia de los servicios financieros" fundando el deber de información en la pretensión de disminuir los problemas de asimetría entre consumidor y proveedor ${ }^{45}$. $\mathrm{Y}$, en tal sentido, su contenido está referido a aquellos aspectos que el legislador ha considerado indispensables para instruir adecuadamente al consumidor financiero sobre los elementos más relevantes del producto o servicio, relacionados, en términos generales, con sus condiciones económicas, la vigencia del contrato, los productos o servicios conexos, la existencia (o no) de un servicio de atención al cliente, del sello SERNAC o de mandatos asociados.

Por su parte, y de conformidad a lo dispuesto en el artículo 62 LPDC., el Decreto N. ${ }^{\circ} 44$, detalla los deberes de información en diversos momentos: al tiempo de la cotización (artículos $4^{\circ}$ a $8^{\circ}$ y 28 a 41), al tiempo de la contratación (artículos $9^{\circ}$ a 11 y 38 a 41), durante la vigencia del contrato (artículos 22 a 26) y otros que se despliegan en diversos momentos, como aquéllos relativos a los cobros ya realizados (artículo 27), a la liquidación para la renegociación de la deuda (artículo 30), para efectos de su término anticipado (artículo 31) o en relación con la publicidad del producto (artículos 33 a 37) ${ }^{46}$. La densidad normativa de las disposiciones en comento resulta abrumadora si se atiende al modo en que se presentan todos los términos financieros (y operacionales) que forman parte de la información que debe ser entregada a los tarjetahabientes. No obstante, si nos situamos al tiempo de la cotización y de la contratación de la línea de crédito subyacente, encontraremos que el reglamento incluye detalladamente todos aquellos elementos que podrían incidir en la decisión de

BAR-GILL, Owen, Seduction by contract. Law, economics and psychology in consumer markets (Oxford, Oxford University Press, 2012), p. 52.

${ }^{44}$ Historia de la Ley N. ${ }^{\circ} 20.555$, p. 6.

${ }^{45}$ De la Maza Gazmuri, Íñigo, Artículo 17 B (letras $\left.A, B, C, D, E, F\right)$, en De la Maza, Íñigo - Pizarro, Carlos (directores) - Barrientos, Francisca (coordinadora), La protección de los derechos de los consumidores. Comentarios a la Ley de protección a los derechos de los consumidores (Santiago, Thomson Reuters, 2013), p. 385.

46 Mella Cáceres, Rodrigo - Larraín Fierro, Álvaro, cit. (n. 26), p. 171. 
apertura de la tarjeta y, luego, de su efectiva utilización. Así, en lo referente al contenido mínimo de estos contratos, el artículo 11 del citado decreto contiene las referencias a los costos de apertura, comisiones, cargos de la tarjeta, costos de administración, operación y/o mantención, costos del crédito, gastos adicionales, cupo total autorizado, condiciones de sobregiro, tasas de interés, etc.

bb) Normativa especifica de las entidades reguladoras. El Compendio de Normas Financieras del BC también establece el contenido mínimo del contrato suscrito entre el emisor y el titular ${ }^{47}$. La mayor parte de dichas disposiciones dan cuenta de los términos del contrato que recaen en el funcionamiento del instrumento, pero no tienen por objeto la entrega de información útil para auxiliar al consumidor en la decisión de su utilización y, en consecuencia, del consumo, en referencia a sus resultados en la economía personal del tarjetahabiente. Los elementos que sí son relevantes para estos efectos se refieren a los datos correspondientes a las comisiones e intereses aplicables, aunque, como veremos, estos tienen una eficacia relativa en lo referente a la decisión de endeudamiento y al riesgo de sobreendeudamiento ${ }^{48}$.

Por su parte, la SBIF agrega normas relativas a la información que debe ofrecerse en las oficinas de atención al público de las entidades emisoras ${ }^{49}$, y, en términos bastante amplios, se agrega la obligación de los bancos de

${ }^{47}$ Sección I.6 del Capítulo III.J.1 del Compendio de Normas Financieras del BC. Sobre la construcción de dichos requisitos como condiciones generales de contratación y sobre la posibilidad de abuso en la redacción de estas condiciones, vid. SwetT, José Tomás, Contratos de adhesión. Tarjeta de crédito bancarias (Santiago, Fundación Fernando Fueyo - Universidad Diego Portales, 2012), p. 15, considerando que, en su momento, tal normativa se encontraba dispuesta en la Circular N. ${ }^{\circ} 17$ de la SBIF, de 28 de abril de 2016, y sus correspondientes modificaciones. Hoy en día, dicha normativa ha sido reemplazada por aquéllas dispuestas en el Capítulo 8.3 de la Recopilación Actualizada de Normas de la SBIF, que replica los términos de la Circular N. ${ }^{\circ} 40$ de la SBIF y sus modificaciones. Sobre el particular, ella únicamente hace referencia a la normativa hoy dispuesta en el compendio de normas del BC. Sobre los términos abusivos en este tipo de contratos con el tarjetahabiente, por supuesto no es imposible ignorar la sentencia en el denominado caso Cencosud (sentencia de la Corte de Suprema, de 24 de abril de 2013, Rol 12.355-11).

${ }^{48}$ Raga Gil, José T., Análisis socio-económico de la insolvencia familiar, en CuENA, Matilde - ColıNo, José Luis (coordinadores), Endeudamiento del consumidor e insolvencia familiar (Cizur Menor, Thomson Reuters Civitas, 2009), p. 50.

49 Sección 4.1. del Capítulo 8.3 de la Recopilación Actualizada de Normas de la SBIF. La formulación de la norma, dirigida al público en general, puede dar pie a su consideración como información básica comercial, en el sentido de que se trata de datos, instructivos, antecedentes o indicaciones que el proveedor debe suministrar directamente al público consumidor, en los términos previstos en el artículo $1^{\circ} \mathrm{N} .^{\circ}$ 
instruir a los usuarios acerca de las precauciones que deben tener en el manejo de sus tarjetas físicas y de los medios en que ellas pueden ser utilizadas, así como de las principales normas que rigen su uso ${ }^{50}$. De nuevo se observa aquí un caudal informativo situado en el deber impuesto a las entidades emisoras en una fase precontractual, referido ahora al posible acceso a la tarjeta de crédito como instrumento de financiamiento del consumo y a las medidas de seguridad para una utilización que evite su uso fraudulento. Otra vez las condiciones económicas se deducen de la referencia a intereses y comisiones, aunque en este caso la obligación del emisor bancario se satisface en su despliegue formal en la oficina, sin poder proyectarse su incidencia en la decisión de consumo, sino asumiéndose un factor recordatorio del consumidor, incluso años después, ante las entidades afiliadas.

\section{Cuestionamientos A LA CONFIGURACIÓN DEL DEBER DE INFORMACIÓN COMO MECANISMO DE PROTECCIÓN DEL} DEUDOR ANTE EL RIESGO DE SOBREENDEUDAMIENTO

\section{Planteamiento general}

El evidente incremento en la emisión y utilización de las tarjetas de crédito ha sido justificado por algunas variables adicionales, destacando aquí aquellas que nos parecen necesarias en relación con el riesgo de sobreendeudamiento. Aunque no se cuenta con estudios sobre la materia en nuestro país, sí nos enfrentamos a fenómenos similares a los existentes en otros contextos. Así, por ejemplo, Scott nos indica que los emisores han logrado convencer a los comerciantes de la aceptación de las tarjetas en la medida en la que puede preverse que los consumidores tienden a gastar más dinero al recurrir al crédito que a otros medios de pago ${ }^{51}$. Por su parte, debe tenerse presente que, si bien las tarjetas permiten hacer un uso del crédito en todos los comercios afiliados a ellas, sin mayor discriminación respecto al tipo de bienes y servicios que por medio de ellos se adquieren o contratan, también deben considerarse los casos en los que esta forma de crédito es utilizada para cubrir las necesidades básicas de la población ${ }^{52}$, especialmente en situaciones de apremio financiero. Con-

$3^{\circ}$ de la LPDC., y debido a ello, deberá entenderse también que dicha información debe ser suministrada de manera que asegure un acceso claro, expedito y oportuno.

${ }^{50}$ Sección 4.3. del Capítulo 8.3 de la Recopilación Actualizada de Normas de la SBIF.

${ }^{51}$ Sсотт, Robert H., III, Credit card use and abuse: a Veblenian analysis, en Journal of Economic Issues 41 (2007) 2, p. 568.

${ }^{52}$ Ramsay, Iain, Consumer credit law, distributive justice and the welfare state, en Oxford 
siderando la estructura social, no es ilusorio pensar que la denominada "democratización del crédito" ${ }^{53}$ y los objetivos de inclusión financiera por medio de las tarjetas de crédito dan cuenta de que parte de la población suple con ellas las deficiencias de sus ingresos. Además del claro reproche que puede efectuarse a las inequidades en la distribución de la riqueza en nuestro país, en este punto el acceso al crédito viene también a reemplazar los esfuerzos del Estado en la dotación de elementos básicos de seguridad social, por cuanto -amparados en el principio de subsidiariedad- se argumenta que ellos pueden ser sustanciados por medio del recurso a las negociaciones entre particulares, suponiendo el recurso al financiamiento para el acceso a la alimentación, salud y educación ${ }^{54}$.

En estos casos, el problema se presenta en dos dimensiones: por una parte, la negativa de crédito a este grupo de la población, sin balancearla con un fortalecimiento de las redes de bienestar público, resultaría en un debilitamiento de su posición social, en la medida en la que no se encontrarían medios sustitutivos adecuados para la satisfacción de tales necesidades básicas (salvo los peligrosos "préstamos informales") $)^{55}$. Por otro lado, la conservación del modelo implica que deberá asumirse que si el crédito es utilizado para esta clase de fines, existe una enorme posibilidad de sobreendeudamiento ${ }^{56}$, sea porque el crédito y, por tanto, las necesidades suplidas, siempre superaron las posibilidades de pago, sea porque la debilidad de los ingresos puede verse condicionada por elementos externos que pasan a impedir el pago de la deuda (enfermedades, cesantía, crisis familiar, entre otros). En ambos casos, dada la infracción de la obligación de pago, los términos contractuales permitirían el cobro de intereses penales o, en su extremo, la suspensión o terminación de la línea de crédito subyacente. Ambos elementos son nocivos para el sujeto. El primero, puesto que el incremento exponencial de la deuda por la aplicación de una tasa de interés más elevada dificultará aún más la satisfacción íntegra de la obligación (artículo 1591 CC) ${ }^{57}$; el segundo porque dejará al sujeto desprovisto de

Journal of Legal Studies 15 (1995), p. 181.

53 Anchával, Hugo, Insolvencia del consumidor (Buenos Aires, Astrea, 2011), p. 18.

${ }^{54}$ Ruz Lártiga, Gonzalo, cit. (n. 16), p. 484.

55 RAMSAY, Iain, cit. (n. 52), p. 182.

${ }^{56}$ ScOTт, Robert H., III, cit. (n. 51), p. 569.

${ }^{57}$ De ahí la relevancia de la reducción de la tasa máxima convencional para los créditos que pueden ser caracterizados como créditos de consumo (hasta $200 \mathrm{UF}$ ), por medio de la incorporación de la regla del artículo 6 bis de la Ley N. ${ }^{\circ} 18.010$, y a la fórmula de cálculo de dicha tasa en el marco de las tarjetas de crédito conforme al artículo 6 ter de la misma ley. Todo ello conforme a las modificaciones incorporadas por la Ley N. ${ }^{\circ} 20.715$, de 2013. 
formas de dar cobertura a las necesidades básicas que lograba con recurso al endeudamiento, produciendo la denominada exclusión social.

El problema en este punto se refiere a que el uso del crédito como soporte del consumo siempre requiere de un concedente de financiamiento, $\mathrm{y}$, al tiempo en que los modelos neoclásicos no consideran su papel en las decisiones tomadas por el consumidor, la cuestión consiste en ponderar un comportamiento racional por parte de los consumidores ${ }^{58}$, lo que es derivado, entre otros, de la información con la que contarían para la toma de decisión en relación con los actos de consumo. Pero en ellos se omite el estudio acerca de las conductas que son desplegadas por el consumidor al tiempo de la utilización del producto en correspondencia a la información concedida. No queremos sostener con lo anterior que el énfasis en la obtención de información, que en nuestro sistema se constituye como uno de los principales medios de protección del consumidor ${ }^{59}$, no tenga efecto alguno. Algún grado de eficiencia podrá concederse a una herramienta que incita a una reflexión sobre la real necesidad de consumo y de sus implicancias económicas ${ }^{60}$, al tiempo que también se articula como un mecanismo que fomenta la transparencia del mercado ${ }^{61}$. El cuestionamiento aquí se centra en determinar si, en el caso en particular del uso de las tarjetas de crédito, puede ser el solo otorgamiento de información la herramienta que puede resolver de forma efectiva los problemas cognitivos y decisorios a los que se ve expuesto el consumidor y que pueden derivar en situaciones de sobreendeudamiento.

Como veremos, el sustrato del funcionamiento del producto requiere de un estándar de conducta racional, la asunción de ciertas habilidades financieras y facultades recordatorias que difícilmente pueden entenderse diseminados en toda la población; del mismo modo como, incluso reconociendo dichas calidades, la proyección de los efectos del crédito en la economía individual o familiar supone también una cierta estabilidad de los ingresos y de los gastos, que, con sus riesgos implícitos, tampoco puede ponderarse con facilidad por los sujetos de crédito.

2. Los problemas derivados de la oportunidad de la información a favor del tarjetababiente

a) El factor recordatorio. En primer lugar, cabe observar el momento en el cual el tarjetahabiente obtiene la información relativa a los términos económicos del producto. Dado que la preocupación del legislador y de

\footnotetext{
${ }^{58}$ ScOTt, Robert H., III, cit. (n. 51), p. 569.

${ }^{59}$ De la Maza, Íñigo, cit. (n. 30), p. 24.

${ }^{60}$ Álvarez Vega, María Isabel, cit. (n. 27), p. 312.

${ }^{61}$ Barrientos Zamorano, Marcelo, cit. (n. 30), p. 95.
} 
los agentes sectoriales se centran en la información que debe concederse al consumidor financiero al tiempo de la contratación de la tarjeta de crédito o durante la vigencia del instrumento, se produce un distanciamiento entre el momento en el que ella se obtiene y aquél en el que se toma, por una parte, la decisión de consumo (que, por la propia estructura de estas tarjetas, resulta vinculada al momento en el que se dispone del crédito) y, más diferido aún, con el momento de decisión del pago de los saldos de la tarjeta, activando los términos relacionados a la tasa de interés aplicable dado el carácter rotativo de la apertura de crédito subyacente ${ }^{62}$. Ello implica que, a diferencia de otros productos financieros, como aquellos en los que la decisión de obtención del crédito se presenta de manera coincidente en el tiempo con la información concedida (v.gr., el crédito hipotecario o un crédito de consumo tradicional), en las tarjetas de crédito la decisión de consumo reposaría sobre un elemento recordatorio que no parece acreditado como una valoración que emplea el consumidor al tiempo de su decisión ${ }^{63}$.

Se exacerban de este modo los problemas de racionalidad imperfecta que, al decir de de la Maza, implica que "el problema no consistiría, únicamente, en que el consumidor disponga de acceso a la información que le permita una adecuada formación del consentimiento, sino que, aun disponiendo de dicho acceso, no necesariamente es capaz de utilizar la información adecuadamente" "64; o de "racionalidad limitada", en el sentido de la necesaria simplificación mental que debe realizar el sujeto ante el enorme acervo informativo a fin de guiar sus decisiones de consumo ${ }^{65}$. Como señala Bar-Gill, la complejidad del contrato entra en juego debido a tal racionalidad imperfecta, en términos que la adopción de decisiones es simplificada, ignorando los factores no destacados de las dimensiones del

${ }^{62}$ Sobre las dificultades del consumidor en la identificación y comprensión de las tasas de interés aplicables en el marco del uso de las tarjetas de crédito, vid. Frank, Joshua M., Do credit card users systematically underestimate their interest rates? Evidence from the Survey of Consumer Finances, en Journal of Public Policy \& Marketing 30 (2011) 1, pp. $133-139$.

${ }^{63}$ Wyer, Jr., Robert S. - Adaval, Rashmi, Social psychology and consumer psychology. An unexplored interface, en WÄNKE, Michaela (editora), Social psychology of consumer behavior (Nueva York - Londres, Psychology Press, 2009), p. 27, sostienen: "[1]as personas que deben efectuar un juicio o decisión no usan normalmente toda la información relevante o los conocimientos previamente adquiridos que tienen disponible [...] En cambio, ellos consideran sólo un subconjunto de esta información y conocimiento que se viene a la mente de manera más rápida y fácil". Traducción del autor.

${ }^{64}$ De la MAZA, Íñigo, cit. (n. 26), p. 27, y con mayor detalle, p. 33.

${ }^{65}$ Andrade Ramírez, Víctor, cit. (n. 26), p. 9. 
precio o sin efectuar cálculo alguno ${ }^{66}$. Frente a ello, no parece exagerado sostener que las dificultades de comprensión del denso acervo informativo terminan siendo reemplazadas por la mera confianza en el emisor ${ }^{67}$ y en las ventajas que se observan como más directas debido a la tenencia de la tarjeta de crédito ${ }^{68}$.

El punto se refleja también en el hecho de que la decisión final de la concesión de crédito no es efectuada por el consumidor ante el proveedor del producto financiero, sino ante la entidad afiliada que acepta la tarjeta como medio de pago. Lo anterior implica que no es este último quien debe conceder información sobre la forma en que deben aplicarse los términos económicos subyacentes a la línea de crédito, que puede incluso desconocer si se trata de una tarjeta no asociada al proveedor de los bienes y servicios. De ello resulta que el consumidor no cuenta con un auxilio in situ para ponderar una decisión de consumo (y, por tanto, de crédito) que se ajuste a una correcta valoración de los efectos concretos que el financiamiento tendrá en la economía personal. Y aún en el caso en el que se activase el citado factor recordatorio, el consumidor se vería enfrentado a un cálculo que parece difícil para el hombre medio, puesto que, sin asistencia alguna, debería aplicar los complejos términos económicos de un contrato suscrito con anterioridad (incluso hace años) a una operación de consumo y financiamiento particular y, a su vez, coordinarla con las decisiones de consumo y financiamiento previamente efectuadas.

b) Elfactor deseabilidad. Al referido elemento recordatorio debe agregarse que éste puede verse alterado en atención a que la decisión de crédito (y, por tanto, de aplazamiento en el pago) se produce de modo coincidente a la decisión de consumo. Sobre el particular, este juicio se encuentra condicionado por el nivel de información relativa a la "deseabilidad" del bien o servicio objeto del consumo, graduándose cognitivamente en una posición superior que aquella que se plantea en relación con la información sobre la posibilidad de obtención de dicho bien o servicio ${ }^{69}$. Asimismo, la

${ }^{66}$ BAR-GILL, Owen, cit. (n. 43), p. 53.

${ }^{67}$ Gomá Lanzón, Fernando, La supuesta complejidad de los llamados productos financieros complejos y la claridad como derecho del consumidor, en PRATS, Lorenzo - CuEna, Matilde (coordinadores), Préstamo responsable y ficheros de solvencia (Cizur Menor, Thomson Reuters Aranzadi, 2014), p. 181.

${ }^{68}$ Especialmente indicativa es la sugerencia de Andrade Ramírez, Víctor, cit. (n. 26), p. 14, respecto a los efectos producidos por los descuentos exclusivos y los programas de fidelización por el uso de una determinada tarjeta.

${ }^{69}$ Eyal, Tal, Liberman, Nira y Trope, Yacov, Psychological distance and consumer behavior. A construal level theory perspective, en WÄNKE, Michaela (editora), Social psychology of consumer behavior (Nueva York - Londres, Psychology Press, 2009), p. 71. 
publicidad actuará como un medio incitar el consumo ${ }^{70}$, de modo que, aun cuando en éste se aprecie un cierto caudal informativo (regido asimismo por estándares de veracidad), no será este su centro de atención. De tal suerte, resultará que, si bien la normativa aplicable dispone la entrega de cierta información básica respecto a los efectos económicos de la operación de financiamiento subyacente, lo anterior no quita que el mensaje publicitario se centre en aquellos aspectos que pretendan el aumento de los niveles de deseabilidad del producto y sólo traten de forma incidental los relativos a su posibilidad de obtención. De este modo, si bien el deber de informar puede configurarse también desde la idea de evitar los errores del consumidor en su decisión de consumo ${ }^{71}$, no parece ser que la publicidad sea el medio consagrado por el ordenamiento para desplegar políticas de educación de los consumidores ${ }^{72}$. Siendo de este modo, si existe un elemento recordatorio a considerar en esta decisión, y éste se presenta de modo más inmediato en lo referente a las características del bien por sobre las condiciones del crédito, podrá concluirse que la decisión estará más fuertemente condicionada por la variable de consumo que por la de crédito.

De lo anterior podemos observar que la decisión de consumo se encuentra ajustada con la idea de una elección inter-temporal y, por tanto, susceptible a ser afectada por el denominado present-biased preference, esto es, por la interacción entre dos sistemas de toma de decisión: "el sistema afectivo, por el que se valora altamente la satisfacción inmediata, descontando todos los periodos futuros; y el sistema deliberativo, en el que se efectúan planes a largo plazo, desenvolviéndose por factores de descuento más elevados"73. Debido a lo anterior, puede tener lugar un "descuento

${ }^{70}$ Álvarez Vega, María Isabel (cit. 27), p. 169.

${ }^{71}$ Barrientos Zamorano, Marcelo, cit. (n. 30), p. 101.

72 Como señala Espada Mayorquín, Susana, Artículo $3^{\circ} \mathrm{F}$ ), en De la Maza, Íñigo - Pizarro, Carlos (directores) - BARrientos, Francisca (coordinadora), La protección de los derechos de los consumidores. Comentarios a la Ley de protección a los derechos de los consumidores (Santiago, Thomson Reuters, 2013), p. 135, la formulación del derecho a la educación, en los términos dispuestos en el artículo $3^{\circ} \mathrm{F}$ ) LPDC., puede efectuarse sólo desde la idea de la asimetría informativa, o extenderse a puntos que persiguen que "los consumidores adquieran una actitud crítica ante el consumo, sin olvidarse de los derechos y responsabilidades ante la explotación y utilización racional de los recursos, la protección al medio ambiente o los problemas actuales de la economía de mercado)". Pero la reconducción de este derecho no parece asociada a la dotación de información por parte del proveedor, que integra el derecho de información reconocido en el artículo $3^{\circ}$ B) LPDC., sino a las funciones atribuidas al SERNAC en los términos del artículo 58 LPDC.

${ }^{73}$ Meier, Stephan - Sprenger, Charles, Present-biased preferences and credit card bor- 
hiperbólico", esto es, que el consumidor prefiera anticipar los beneficios de la obtención del bien o servicio requerido sin efectuar un sacrificio patrimonial inmediato ${ }^{74}$. Lo anterior tiene especial importancia respecto a aquellos productos o servicios con precios que superan la disponibilidad de dinero o el presupuesto del consumidor, o en los que la existencia de un sustituto en el tiempo intermedio tiene, en el agregado temporal, un valor superior, o que no tiene realmente un sustituto ${ }^{75}$. Ello puede dar lugar al denominado "sobreendeudamiento activo", entendido éste como "aquellos supuestos en los que el consumidor provoca en forma dolosa, o al menos negligente, su propio estado de insolvencia aumentando su endeudamiento excesiva o irreflexivamente [...], pudiendo llegar incluso a niveles de conducta compulsiva" ${ }^{\text {"76. }}$

c) El factor del cálculo del riesgo financiero. El asunto del que tratamos también se refleja en la idea de la ausencia de control del destino del crédito asociado a la tarjeta, funcionando como un método de financiamiento que, concedido dentro de los límites dispuestos en la apertura de crédito, presenta una operatoria libre de costos de transacción para el consumidor al tiempo de su uso ${ }^{77}$. No existiendo intervención por parte del emisor en la delimitación de los riesgos inmanentes en la decisión de consumo que efectúa el tarjetahabiente, se presenta una diferencia ostensible con

rowing, en American Economic Journal: Applied Economies 2 (2010) 2, p. 194 (n. 1). Traducción del autor.

${ }^{74}$ De ahí que Meier, Stephan - Sprenger, Charles, cit. (n. 73), p. 195 concluyan que el present bias se encuentra íntimamente relacionado con mayores saldos en las líneas rotativas subyacentes a la tarjeta de crédito. Sobre este problema, advertido desde la lógica de la "miopía" que conlleva la subestimación de los costos futuros, BAR-GILL, Owen, cit. (n. 43) pp. $83-87$.

${ }^{75}$ Durkin, Thomas A. - Elliausen, Gregory - Staten, Michael E. - Zywicki, Todd J., cit. (n. 17), p. 9.

76 Álvarez Vega, María Isabel, cit. (n. 27), p. 52.

77 Esta idea es la que puede generar una posición favorable del consumidor al uso de la tarjeta de crédito frente a otras formas de financiamiento que, contando con una operatoria en la que se procede conforme a una solicitud y estudio previo, parece bastante menos apetecible para el tarjetahabiente que quiere adelantar la satisfacción de sus necesidades de consumo. Lo anterior se deduce incluso del doble propósito de las tarjetas de crédito, funcionando tanto como un mecanismo para el financiamiento, como un modo de obtención de préstamos en forma de "avances en efectivo" en los que se simplifica enormemente el trámite necesario para la obtención de préstamos en menor escala. Ello aun cuando el consumidor podría obtener mejores condiciones financieras a través de medios de financiamiento presenciales, dado el análisis particular que puede ser efectuado por la entidad de crédito. Sobre este aspecto, Brito, Dagobert L. - Hartley, Peter R., Consumer rationality and credit cards, en Journal of Political Economy, 103 (1995) 2, p. 402. 
otros modelos de financiamiento personal (v.gr., financiamientos para la adquisición de bienes duraderos, como inmuebles o vehículos $)^{78}$, por lo que el análisis del citado riesgo debe ser llevado a cabo por el emisor al tiempo de la contratación de la tarjeta ${ }^{79}$. De ahí que en una lógica en la que la apertura de crédito se ofrece para un arco temporal bastante distendido, en el que el emisor ya no podrá efectuar control alguno sobre la base de una mutación de las condiciones personales del tarjetahabiente ni tendrá oportunidad para ponderar la posición de riesgo que este podría asumir al tiempo del uso del instrumento, aquél deberá asumir los peores escenarios posibles, justificando ello la delimitación de los montos máximos de disposición y las altas tasas de interés asociadas al uso de las tarjetas de crédito.

Por su parte, ahora desde la perspectiva del consumidor, el carácter rotativo de la línea de crédito y su extensión temporal supone que el uso del instrumento no está condicionado a una decisión única de consumo, sino a decisiones múltiples que tienen lugar en momentos y ante entidades afiliadas diversas, las que no siempre pueden ser racionalmente coordinadas por el consumidor al tiempo de decidir hacer uso de la tarjeta. Así, si bien la información pudo haberse entregado de manera clara en un momento anterior, sea al tiempo de la contratación o al recibir los correspondientes estados de cuenta, la comprensión de las consecuencias económicas que pueden derivarse del uso reiterado de la tarjeta implica asumir ciertas destrezas particulares por parte del consumidor. De este modo, ha de suponerse que éste podrá recordar (y, luego, ponderar) factores tales como el cupo utilizado, la proyección del pago mínimo a ser programado en el próximo estado de cuenta para no dar lugar a intereses penales, la oportunidad de pago de cada operación realizada (en particular, si algunas han sido pactado en cuotas), entre tantas otras; y, luego, con tales antecedentes, calcular los flujos disponibles que sean requeridos para el oportuno pago de la deuda.

d) El factor de la dilación de la elección del momento y la forma de pago. En realidad, los efectos económicos de la decisión de consumo deberán ser asumidos en un momento posterior, al tiempo en el que el emisor de la tarjeta le recuerde las consecuencias económicas de su decisión de consumo y aplique los términos y condiciones pactadas en el contrato de línea de crédito subyacente. Ello, al tiempo del envío de la correspondiente

${ }^{78}$ White, Michelle, Bankruptcy reform and credit cards, en Journal of Economic Perspectives 21 (2007) 4, p. 180.

${ }^{79}$ Lo anterior se deriva también de las teorías culturales del consumo, conforme a las cuales la facilitación del acceso al crédito, sin valoraciones específicas sobre la real capacidad de pago, produce una incitación al gasto no sólo por necesidad, sino también por el simple querer (Sсотт, Robert H., III, cit. [n. 51], p. 570). 
cartola ${ }^{80}$. En este punto, el consumidor ya no se enfrentará (como en los productos financieros tradicionales) a una tasa de interés fija y a un calendario de pagos previamente definido, sino a una nueva decisión: podrá transformar el uso de la tarjeta en un mero medio de pago, sin intereses asociados, solucionando el importe total de la deuda generada por la efectiva utilización de la tarjeta ${ }^{81}$; o transformarla en un medio de financiamiento aplazado, efectuando el pago mínimo pactado, activando así el devengo de intereses y otras comisiones aplicables ${ }^{82}$.

Es la segunda elección la que es también asistida por el emisor, en los términos exigidos por el Decreto N. ${ }^{\circ} 44$, de 2012. Ello, en el sentido de la regulación de la información que debe ser comunicada con una periodicidad mensual por el emisor al tarjetahabiente, cuyo contenido y formato ha quedado determinado por los artículos 22 a 24 del citado decreto. Conforme a ello, el consumidor obtiene información general relativa al cupo total, al utilizado y al disponible; a la tasa de interés y carga anual equivalente vigente y a la carga de prepago; información detallada sobre el periodo de facturación anterior, expresando el saldo adeudado al inicio y al término de dicho lapso, como asimismo del monto facturado y pagado en el mismo; información sobre el periodo actual, indicando el lugar, fecha y descripción de la operación, el monto a cobro y el monto a pagar (dependiente de si la utilización de la tarjeta se efectuó o no en cuotas) y expresando el monto total facturado, el monto mínimo a pagar y el costo monetario del prepago.

No obstante, no debe ignorarse que, al tiempo de efectuar esta nueva decisión, la operación de consumo (y, por tanto, la solicitud de financiamiento) ya fue realizada, de manera que la determinación de si se efectuará o no un pago completo del saldo de la tarjeta estará condicionada a factores que no se satisfacen únicamente con la información recibida ${ }^{83}$ Y, en ello,

${ }^{80}$ Como indica Armone Gibson, Enrique, cit. (n. 37), p. 32, el consumidor manifiesta una "carencia de conocimiento, o el desinterés por conocer, en lo que se refiere a finanzas. Parece poco preocupado por el precio de las cosas si compra a plazo; lo que le interesa es la cuota mensual y su capacidad para solventarla".

${ }^{81}$ Se trata éste de un periodo de gracia concedido al tarjetahabiente, en el que no se computarán los intereses devengados entre el momento en que tuvo lugar el consumo y el pago del saldo de la tarjeta, en caso de que este sea completo. En este sentido, Brito, Dagobert y Hartley, Peter, cit. (n. 77), p. 401.

${ }^{82}$ White, Michelle, cit. (n. 78), p. 181.

${ }^{83}$ Aunque alguna referencia especial debe darse a las últimas secciones del estado de cuentas, que, conforme a los artículos 22 y 23 del Decreto N. ${ }^{\circ} 44$, de 2012, deben hacer referencia a los vencimientos de los próximos cuatro meses, el próximo periodo de facturación, un gráfico que describa la evolución del monto total facturado respecto de los pagos efectuados en los últimos 6 meses e información sobre 
tiene clara importancia los problemas de liquidez experimentados al tiempo de tomar la citada decisión, prorrogando la fecha de pago y activando los intereses predispuestos ${ }^{84}$. En este punto, como indica AusubeL, existe una falla en la actitud de los consumidores puesto que estos "no son capaces de anticipar la alta probabilidad de que éstos deberán pagar intereses en sus saldos pendientes" ${ }^{\prime 5}$, situación que, a mi juicio, se presenta por dos motivos: primero, porque no puede asumirse que el consumidor entienda de forma cabal cómo operan los intereses en este complejo producto al tiempo en que se efectúa la decisión de consumo, y, luego, que el momento en el que dicha explicación es concretada numéricamente al nivel del estado de pagos (o cartola) ya no es posible deshacer una decisión de consumo materializada, lo que evidencia las dificultades derivadas de la distancia temporal entre la decisión de consumo y la aplicación de los términos del financiamiento.

e) Consecuencias. La particularización de la forma y del momento en que se desarrolla el deber genérico de información previsto en la LPDC. en el marco de la regulación de las tarjetas de crédito, descansa sobre la idea de que su contenido es aquél que el regulador ha estimado necesario para que "la voluntad del consumidor se forme correctamente" ". A su vez, se revela bajo el diseño de una herramienta estandarizada que facilita la toma de decisiones por parte del consumidor ${ }^{87}$, sin que ella se encuentre necesariamente ajustada a las particularidades del tarjetahabiente.

Si ello es así, la densidad normativa expresada en los apartados anteriores sería un claro indicio de las complejidades de los términos financieros asociados a la tarjeta, de modo que podemos recordar la crítica que señala que el exceso de información puede incluso derivar en problemas similares a los de la ausencia de información ${ }^{88}$. Basados en lo anterior, no es difícil anticipar las dificultades a las que se enfrenta el consumidor medio ${ }^{89}$ al

los costos por atraso (intereses moratorios y gastos de cobranza). Esta información se dirigiría a influir en las decisiones del consumidor, tanto en proyectar eventuales decisiones de consumo futuro como para llevar a cabo pagos que minimicen la carga económica del instrumento.

${ }^{84}$ Álvarez Vega, María Isabel, cit. (n. 27), p. 242.

${ }^{85}$ Ausubel, Lawrence M., The failure of competition in the credit card market, en The American Economic Review 81 (1991) 1, p. 71 (n. 42). Traducción del autor.

${ }^{86}$ De la MAZa, Íñigo, cit. (n. 26), p. 45.

${ }^{87}$ Andrade Ramírez, Víctor, cit. (n. 26), p. 6.

${ }^{88}$ Barros Bourie, Enrique, Tratado de responsabilidad extracontractual (Santiago, Editorial Jurídica de Chile, 2006), p. 1015, y Andrade Ramírez, Víctor, cit. (n. 26), p. 12.

${ }^{89}$ Considérese al efecto que la Directiva 2005/29/CE, de 11 de mayo de 2005, relativa a las prácticas comerciales desleales de las empresas en sus relaciones con los 
tiempo de decidir sobre su utilización y las condiciones de pago, dado que no es tan evidente que en este caso pueda utilizarse la caracterización del homo economicus que actúa guiado por la razón ${ }^{90}$, derivado tan solo de la información obtenida ${ }^{91}$. Como señala Ramsay, esta clase de reglas, "basadas en una asunción neoclásica del análisis económico del derecho, contextualiza los resultados del mercado como un reflejo de intercambios voluntarios beneficiosos para ambas partes y reglas de derecho privado que persiguen primariamente un papel limitado en la reducción de los costos de transacción" $" 92$. De este modo, si el diseño normativo se basa en incrementar los niveles de racionalidad de los sujetos sobre la base de la provisión de información por parte del concedente del crédito, pasaría a asumirse que, por el solo cumplimiento de los deberes informativos por parte del emisor (hoy estandarizados), la responsabilidad del endeudamiento recae en el consumidor ${ }^{93}$, volviendo a la lógica del Código Civil en que las tutelas ante el incumplimiento y la insolvencia se despliegan a favor del acreedor, con escasa atención a la posición el deudor ${ }^{94}$.

\section{El problema del sesgo optimista (optimism bias)}

Un segundo problema se ofrece en atención a las distancias intertemporales que se presentan entre la decisión de consumo y el aplazamiento de su pago, haciendo uso de las diversas herramientas que concede la utilización misma de la tarjeta de crédito. El hecho de que la mayor parte de los costos asociados a la tenencia y uso de la tarjeta de crédito se encuentren diferidos provoca, en este sentido, que el consumidor los sub-

consumidores en el mercado interior, describe a este consumidor medio como aquel que está normalmente informado y es razonablemente atento y perspicaz, teniendo en cuenta los factores sociales, culturales y lingüísticos. Sobre las dificultades de la consideración de dicho consumidor medio en modelos de negocio predatorios, vid. Paterson, Jeannie Marie y BRODY, Gerard, "Safety net" consumer protection: using probibitions on unfair and unconscionable conduct to respond to predatory business models, en Journal of Consumer Policy, 38 (2015) 3, pp. 350-351.

90 Andrade Ramírez, Víctor, cit. (n. 26), p. 8.

${ }^{91}$ Como señala Cuena Casas, Matilde, El sobreendeudamiento privado como causa de la crisis financiera y su necesario enfoque multidisciplinar, en PRATS, Lorenzo - CUENA, Matilde (coordinadores), Préstamo responsable y ficheros de solvencia (Cizur Menor, Thomson Reuters/Aranzadi, 2014), p. 31, “[n]o basta una mera protección contractual del consumidor (inundándole de información que no comprende), estrategia que se ha evidenciado a todas luces insuficiente".

${ }_{92}$ Ramsay, Iain, cit. (n. 52), p. 179. Traducción del autor.

${ }^{93}$ Sсотт, Robert H., III, cit. (n. 51), p. 569.

${ }^{94}$ Goldenberg Serrano, Juan Luis, La responsabilidad patrimonial universal y el sobreendeudamiento de la persona deudora, en Corral, Hernán y Manterola, Pablo (editores), Estudios de Derecho Civil XII (Santiago, Thomson Reuters, 2017), pp. 239-244. 
estime al tiempo de tomar las decisiones de contratación, financiamiento y consumo ${ }^{95}$. En esta materia se conjugan, basado en el planteamiento de la economía conductual, tendencias a enaltecer las capacidades y menospreciar las debilidades personales, presentes o proyectadas.

a) La sobreestimación del factor positivo (destrezas y autocontrol). Desde el punto de vista del enaltecimiento de sus destrezas, verbalizar la susceptibilidad de verse expuesto al riesgo implicaría el reconocimiento previo de una debilidad comparativa. Así, si el modelo de consumidor racional se ponderara sobre esta variable, éste no acudiría con tales antecedentes a la solicitud del crédito puesto que terminaría alertando al concedente de la existencia de riesgos que, incluso estadísticamente, no son apreciables respecto al sujeto. Al contrario, para la obtención del resultado querido (el acceso a la fuente de financiamiento), lo habitual será destacar la estabilidad patrimonial y las proyecciones futuras de ingresos y gastos, de manera de ofrecer una posición minimizadora de cualquier incidencia negativa en los mismos. En este punto, la distorsión también se presenta en atención a una errada proyección de un determinado estándar que el consumidor estima adecuado para efectuar la comparación. Así, por ejemplo, si los riesgos del sobreendeudamiento son advertidos sólo con relación a un cierto grupo etario, respecto a quienes desarrollan una determinada actividad o para quienes llevan a cabo conductas desordenadas con sus finanzas personales, el consumidor negará su exposición al riesgo si no se considera o logra reconocerse integrado en una de tales categorías.

Adicionalmente, aun cuando el monto máximo disponible exceda con creces la real posibilidad de pago por parte del tarjetahabiente, este tenderá a aceptar dicho cupo (o los incrementos que continuamente pueden ofrecerse, incluso telefónicamente), dado que sobreestima sus poderes de autocontrol ${ }^{16}$. En este punto, el consumidor puede haber sido puesto en una situación de riesgo por el propio concedente del crédito, especialmente cuando este no ha llevado a cabo una apropiada valoración de la solvencia del sujeto, presente y estadísticamente proyectada, considerando que el consumidor medio no tiene destrezas suficientes para efectos de llevar a cabo la mentada estimación del riesgo. Si bien ello puede presentarse en cualquier forma de crédito al consumo, en el caso de las tarjetas de crédito de base rotativa lo anterior se ve reforzado, dada la distancia temporal existente entre el momento de la contratación (o aumento de cupo) y la decisión de consumo ${ }^{97}$, como también por el hecho de que en los préstamos de consumo habituales el cronograma de pagos y la fijación de

\footnotetext{
95 Bar-GiLl, Owen, cit. (n. 43), p. 53.

${ }^{96}$ BAR-GILL, Owen, cit. (n. 43), p. 83.

${ }^{97}$ Bar-Gill, Owen, cit. (n. 43), p. 85.
} 
intereses se encuentra pactada al inicio, y no es dependiente de la decisión del tarjetahabiente al recibir la cartola.

b) La subestimación del factor negativo (la ponderación de la solvencia futura). Factores relacionados con las dificultades que el consumidor experimenta en la apreciación de los riesgos a los que puede enfrentarse en su ciclo de vida (o, al menos, en el ciclo de vigencia del crédito), se reducen en un comportamiento optimista al tiempo de tomar las decisiones de endeudamiento a mediano y largo plazo derivados del consumo. Es esta misma estabilidad promedio de los flujos de los consumidores (esencialmente derivadas de sus ingresos laborales) ${ }^{98}$ la que ha propiciado la existencia misma de estas formas de financiamiento, considerando incluso aquellos periodos en los que pueden existir ciertas alteraciones temporales (como mayores gastos en ciertas épocas de la vida ${ }^{99}$. De ahí la usual comprensión de que, si el concedente del crédito ha conferido una línea de financiamiento a mediano o largo plazo sobre la base de una aparente ponderación de la estabilidad patrimonial del tarjetahabiente, éste puede asumir de manera razonable que dicho análisis ha minusvalorado la probabilidad de riesgo. Esta aproximación conlleva un riesgo ya que puede dar pie al denominado "sobreendeudamiento pasivo", es decir, aquél que "viene producido por causas ajenas a la voluntad del consumidor de la más variada índole: pérdida del puesto de trabajo, accidentes, enfermedades, fallecimiento del cónyuge, sanciones tributarias, disolución del matrimonio o aumento inesperado de la familia"100.

El problema del sobre-optimismo ha sido estudiado desde la perspectiva de la psicología para una serie de materias ${ }^{101}$. En general, se refiere a los casos en los que existe una tendencia de las personas para considerar que ellas se encuentran menos expuestas a sufrir eventos negativos y, por el contrario, más proclives a experimentar eventos positivos ${ }^{102}$. Como es

98 Como se indica en los considerandos 7 y 8 de la Resolución del Consejo de la Unión Europea de 26 de noviembre de 2001 relativa al crédito y al endeudamiento de los consumidores (2001/C364/01), la vinculación entre el crédito al consumo, la (in)estabilidad de los ingresos y el endeudamiento excesivo es evidente.

99 Durkin, Thomas A. - Elliausen, Gregory - Staten, Michael E. - Zywicki, Todd J., cit. (n. 17), p. 10.

100 Álvarez Vega, María Isabel, cit. (n. 27), p. 53.

101 Como nos señalan Massey, Cade - Simmons, Joseph P. - Armor, David A., Hope over experience: desirability and the persistence of optimism, en Psychological Science 22 (2011) 2, p. 274, las personas son excesivamente optimistas respecto al matrimonio, al trabajo, a los deportes, a la salud y a las expectativas de vida.

102 Helweg-Larsen, Marie - Shepperd, James A., Do moderators of the optimistic bias affect personal or target risk estimates? A review of the literature, en Personality and Social Psychology Review 5 (2001) 1, p. 74. 
fácilmente observable, este optimistic bias supone un punto de comparación con otros que integran un grupo de riesgo, de modo que el individuo en cuestión tiende a ponderarse en mejor situación que los demás. Si se indaga en las razones por las cuales se presenta tal distorsión, ella se justifica, entre otros, por la falta de experiencias personales o cercanas en relación con el citado riesgo, el enaltecimiento de las destrezas propias y la existencia de ciertos errores cognitivos ${ }^{103}$.

Aplicando lo anterior en la materia que nos interesa, es muy probable que el consumidor proyecte sus ingresos y gastos de manera estable, sin mayores contratiempos. Así, si no se ha visto expuesto a situaciones de riesgo, no existen claros motivos para apreciar una vulnerabilidad. De tal suerte, si no ha experimentado aquellos trágicos eventos antes mencionados, parece conductualmente coherente una actitud que los desatienda, puesto que no resultaría razonable que una persona prevea, en el marco de su decisión de consumo y endeudamiento, que en un tiempo cercano perderá su trabajo, sufrirá enfermedades o experimentará una crisis familiar, a menos que pueda observar señales claras que incrementen la factibilidad de tales hechos.

c) Consecuencias. El principal problema del sobre-optimismo se refiere a que éste afecta la realización de esfuerzos que tiendan a la reducción de dichos riesgos ${ }^{104}, \mathrm{o}$, al menos, a su correcta ponderación para la adopción de decisiones que puedan tener un impacto futuro. Así, será usual que el consumidor asuma que los términos financieros pactados en el contrato de apertura subyacente a la tarjeta de crédito se aplicarán en el régimen de solvencia y liquidez patrimonial existente al momento de su contratación, de modo que estimará que los ingresos futuros serán suficientes para darles adecuada cobertura, pero desestimará, por ejemplo, aquellos intereses penales derivados del incumplimiento. Todo lo anterior, bajo la expectativa de que ellos no se devengarán en virtud de la suficiencia de tales flujos en atención a una perpetua estabilidad ${ }^{105}$.

Conforme a lo anterior, la ponderación de los riesgos llevada a cabo por el consumidor, si es que ella se presenta, será imperfecta y podrá implicar decisiones de consumo y financiamiento erradas al no contar con herramientas suficientes para provocar un ajuste verdaderamente adecuado a sus capacidades patrimoniales Por su parte, la calificación efectuada por el emisor de la tarjeta no se detiene en la auto-evaluación realizada por el consumidor al tiempo que el otorgamiento del crédito, ni se efectúa

103 Weinstein, Neil D., Optimistic biases and personal risk, en Science 246 (1989) 4935, p. 1232.

104 Weinstein, Neil D., cit. (n. 103), p. 1232.

${ }^{105}$ Frank, Joshua M., cit. (n. 62) p. 134. 
únicamente sobre la perspectiva de su situación patrimonial actual, sino que se ajusta a una proyección estadística de flujos ${ }^{106}$. Pero dichas variables no son conocidas por el consumidor ni se encuentran incorporadas en el deber de información al que hacíamos referencia, incrementando el riesgo de sobreendeudamiento.

\section{EL FORTALECIMIENTO DEL DEBER DE ASESORÍA PARA \\ LA CONSTRUCCIÓN DE UN RÉGIMEN DE “PRÉSTAMOS RESPONSABLES"}

\section{Hacia una recalificación de las reglas de responsabilidad patrimonial universal} $y$ de la asignación del riesgo de sobreendeudamiento

Como expresa Bar-Gill, "las percepciones erróneas de los tarjetahabientes que subyacen a los costos de bienestar identificados también cualifican la presunción de no intervención del paradigma expresado por la libertad contractual. Si una de las partes contratantes malentiende las consecuencias futuras del contrato, entonces el poder normativo del consentimiento contractual es significativamente debilitado" ${ }^{107}$. Añádase en este punto el marcado "analfabetismo financiero" de la población, que, en el caso chileno, ha sido puesto de manifiesto por parte del Servicio Nacional del Consumidor ${ }^{108}$ y, más recientemente, por la Organización para la Cooperación y el Desarrollo Económicos ${ }^{109}$. Asimismo, adviértase que el mercado de las tarjetas de crédito incluye a consumidores en posición de vulnerabilidad, entendiendo por tales a quienes no pueden resguardar adecuadamente sus intereses y que, en consecuencia, pueden ser fáciles destinatarios de estrategias de mercadotecnia que invitan al sobreconsumo o de términos contractuales que alteran su percepción respecto de las consecuencias económicas derivadas de su uso ${ }^{110}$.

106 Álvarez Vega, María Isabel, cit. (n. 27), p. 54.

107 BAR-GILL, Owen, cit. (n. 43) p. 55. Traducción del autor.

108 SERNAC, Educación financiera en jóvenes: clave para un desarrollo económico saludable [visible en internet: http://www.sernac.cl/wp-content/uploads/2015/08/ Educaci $\% \mathrm{C} 3 \% \mathrm{~B} 3 n$-financiera-en-j $\% \mathrm{C} 3 \% \mathrm{~B} 3$ venes -clave-para-un-desarrolloecon $\% \mathrm{C} 3 \% \mathrm{~B} 3$ mico-saludable-vf.pdf]. A partir de un estudio encargado a ADIMARK, el SERNAC concluyó que 3 de cada 4 estudiantes ignora qué es un "producto financiero" y qué es una "tasa de interés", al tiempo que 3 de cada 5 no reconocen el crédito más conveniente a partir de la indicación de la "carga anual equivalente".

109 OECD, PISA 2015 Results (Volume IV): Students' Financial Literacy (París, PISA, OECD Publishing, 2017), reporta que un 38\% de los estudiantes chilenos se encuentra bajo la línea base de competencias en educación financiera y sólo un 5\% se encuentra en el nivel superior.

${ }^{110}$ Paterson, Jeannie Marie y Brody, Gerard, cit. (n. 89), p. 332. 
En consecuencia, constatadas las dificultades reseñadas en el acápite anterior, resulta claro que la aproximación del ordenamiento patrio es completamente insuficiente en la identificación de los citados problemas cognitivos y conductuales del tarjetahabiente, y, conforme a ellos, desplegar un modelo de protección que resulte más certero. No parece coherente que el ordenamiento chileno sólo emplee herramientas informativas, generales y estandarizadas, a efectos de sostener un modelo de responsabilidad del deudor desplegado especialmente en las reglas pertinentes del Código Civil, sin advertir que éste reposa en ciertas bases fácticas que no se reducen a un equilibrio en el conocimiento de los términos financieros del contrato. En este sentido, el propósito de configurar las bases de un sistema más ajustado a la realidad de esta clase de endeudamiento requiere delimitar los campos en los que el régimen general de las obligaciones, especialmente contractuales, debe ser reformulado a partir de las ideas de la corresponsabilidad del acreedor ${ }^{111}$, especialmente en los casos en los que el mercado financiero "acusa algunos rasgos de irresponsabilidad en el otorgamiento del crédito, provocados por una facilitación descontrolada del acceso al crédito, sobre todo en sectores vulnerables" ${ }^{\prime 12}$.

Para estos efectos, debe tenerse presente que el sustrato del sistema tradicional previsto en el Derecho civil se basa en un incremento de la tutela de los acreedores al desencadenarse la insolvencia el deudor, cuya contrapartida se constata en una débil protección del deudor insolvente. Al efecto, la conducción de la coercitividad de las obligaciones por medio de la regla de la responsabilidad patrimonial universal (art. 2465 CC) $)^{113}$, envuelve un modelo en que la mentada insolvencia del deudor constituye un estado que debe activar una mayor protección para el acreedor a fin de dar plena eficacia al principio de responsabilidad civil. Un declive en la solvencia del deudor justifica la consagración de normas tales como las relativas a la caducidad legal del plazo (art. 1496 CC), la matización de la obligación de entrega por parte del vendedor (art. 1826 CC), la exigencia de la constitución de fianzas (art. 2348 CC), y los denominados derechos auxiliares contemplados especialmente en los arts. 2466 y 2468 CC.

111 Vid. Paterson, Jeannie Marie - Brody, Gerard, cit. (n. 89), p. 333, al considerar que en esta clase de modelos de negocios se constata que el acreedor puede haber contribuido a la creación del riesgo de que el consumidor vulnerable "haya celebrado contratos que no entiende y termine con productos que no son apropiados para sus necesidades o que simplemente no pueden pagar". Traducción del autor.

112 Ruz Lártiga, Gonzalo, cit. (n.16), p. 502.

${ }^{113}$ Para un completo estudio sobre esta regla, vid. Capilla Roncero, Francisco, La responsabilidad patrimonial universal y el fortalecimiento de la protección del crédito (Madrid, Ministerio para las Administración, 1989). 
En cambio, la regla de responsabilidad es especialmente dura desde la perspectiva del deudor, porque se considera que sólo el deudor solvente es un deudor responsable ${ }^{114}$. De este modo, al deudor en desventura se le aprecia bajo un estándar de sospecha, que viene dado por el solo hecho de haber administrado su patrimonio llevándolo a la insolvencia. De ahí que el mínimo espacio que se le confiere para la protección de sus intereses, articulado por medio del "pago por cesión de bienes", supone que el deudor debe desvirtuar la presunción de culpabilidad en la generación de la insolvencia, en la medida en la que el deudor debe acreditar que el estado patrimonial crítico proviene de "accidentes inevitables" (arts. 1614, 1616 y 1617 CC). Solo así, y luego de la entrega de todos sus activos embargables (arts. 2465 y 1618 CC), se consigue la postergación de la agresión a sus bienes futuros por medio del beneficio de competencia, dejándole lo indispensable para su modesta subsistencia, pero siempre con cargo de la devolución del crédito cuando mejore su fortuna (art. 1626.6 CC) ${ }^{115}$.

De esta manera, la lógica que se trasunta en la regla de responsabilidad termina asumiendo que el riesgo de insolvencia siempre terminará gravando al deudor, quien, ni siquiera en caso de circunstancias extraordinarias, podrá desatender aquello a lo que se ha obligado ni a las consecuencias de su incumplimiento. Se configura así un reproche por no efectuar una adecuada ponderación de tal riesgo habida cuenta de las fuerzas de su patrimonio, actuales y proyectadas durante toda la vigencia del crédito. Desde la perspectiva contractual, subyace en ello el respeto irrestricto del pacta sunt servanda (art. 1545 CC), suponiendo el nacimiento de una obligación basada en una negociación previa, equilibrada e informada, en la que el acreedor no se considera responsable ni partícipe de la insolvencia de su deudor, ni en una posición de haberla previsto completamente a fin de aplacar sus efectos.

La pregunta se sitúa, entonces, en advertir si el modelo clásico aún se justifica en los casos en los que los problemas cognitivos y conductuales antes anotados pueden interferir en la citada asignación del riesgo y, en caso de negativa, si es posible asumir que el concedente del crédito debe tener una participación más activa que la mera dotación de información para intentar aplacarlo. En otras palabras, podemos cuestionar si es admisible la construcción de un sistema que avance hacia un estándar de corresponsabilidad entre deudores y acreedores, en que el primero

114 Díez-Picazo, Luis, Fundamentos de Derecho civil patrimonial, Las relaciones obligatorias (6. ${ }^{a}$ edición, Cizur Menor, Thomson Civitas, 2008) II, p. 152.

115 Goldenberg Serrano, Juan Luis, La responsabilidad patrimonial universal y el sobreendeudamiento de la persona deudora, en Corral, Hernán y Manterola, Pablo (editores), Estudios de Derecho Civil XII (Santiago, Thomson Reuters, 2017). 
concede información fidedigna sobre su situación personal y patrimonial, y el segundo, en tanto entidad profesional, emplea dicha información (y otra que puede obtener de fuentes públicas) para llevar una correcta ponderación sobre la adecuación del producto financiero a las necesidades y capacidades de pago del consumidor. Como se observa, en esta materia no nos estamos desviando de la justificación habitual del tratamiento del contrato por adhesión en el contexto del Derecho de consumo ${ }^{116}$, generando, principalmente a partir de los estándares de buena fe y del necesario reequilibrio de las posiciones de los contratantes, una serie de criterios adicionales que desplazan (aun parcialmente) la responsabilidad hacia el proveedor, predisponente de las cláusulas contractuales.

Como indica Carvajal Ramírez, a partir de la letra g) del artículo 16 de la Ley N. ${ }^{\circ} 19.496$ es posible advertir que el criterio matriz de interpretación de los contratos por adhesión no puede encontrarse en voluntades o intenciones comunes (como se impone a partir del artículo 1560 CC), sino en parámetros objetivos que se corresponden a la finalidad del contrato ${ }^{117}$. En este sentido, no parece posible que la información entregada para configurar un aparente equilibrio a las partes pueda dotar de coherencia a un sistema que no basa la construcción del contrato por adhesión en la voluntad expresada en razón de la información concedida, ni a partir de dicha información puedan entenderse completamente resueltas las obligaciones asumidas por el proveedor si se atiende al propósito práctico del contrato. Por ello, creo que un análisis análogo al empleado para justificar la intervención legislativa (y, luego, judicial) en el contrato ${ }^{118}$, puede ser utilizado ya no sólo en lo que se refiere a los términos jurídicos de las obligaciones asumidas por las partes, sino también a las proyecciones económicas derivadas de la contratación de productos y servicios financieros, en especial, a medida en la que se acrecienta la complejidad de su comprensión, como en el caso de las tarjetas de crédito.

116 Para un resumen sobre las justificaciones para el combate de las cláusulas abusivas, vid. BARAONA González, Jorge, La nulidad de las cláusulas abusivas en la Ley N. 19.496: naturaleza y régimen, en BarRIENTOS Camus, Francisca (coordinadora), Condiciones generales de la contratación y cláusulas abusivas (Santiago, Ediciones Universidad Diego Portales, Cuadernos de Análisis Jurídico, 2014), p. 235.

117 Carvajal Ramírez, Patricio-Ignacio, Tipicidad contractualy derecho de los consumidores. Artículo 16, letrag) de la Ley N. 19.496, en Elorriaga DE Bonis, Fabián (coordinador), Estudios de Derecho Civil VII (Santiago, AbeledoPerrot, LegalPublishing Chile, Thomson Reuters, 2012), p. 443.

118 Momberg Uribe, Rodrigo, El control de las cláusulas abusivas como instrumento de intervención judicial del contrato, en Revista de Derecho (Universidad Austral de Chile), 26 (2013) 1, pp. 9-27. 


\section{Bases para la configuración de un deber de asesoría por parte del emisor de la} tarjeta

Atendidas las características de la tarjeta de crédito antes enunciadas, la pretensión es avanzar en el reconocimiento de medidas que auxilien a la construcción de un modelo financiero fundado en la idea de los "préstamos responsables" "119 , tipificando conductas e implementando sanciones para los concedentes del crédito que las infringen ${ }^{120}$, erigiéndolas sobre la base de una corresponsabilidad entre el prestamista y el consumidor en la asunción del riesgo de sobreendeudamiento ${ }^{121}$. Se trata de un movimiento que hunde sus raíces en el Derecho francés a partir de la década de los ochenta del siglo pasado, mediante un sistema que "ha querido responsabilizar a los bancos obligándoles a informar a los prestatarios y a advertirles frente al exceso de crédito, sancionándoles si prestan a una persona con un sobreendeudamiento previsible"122. Ello supone un comportamiento abusivo por parte del concedente del crédito si no informa los riesgos del exceso de consumo, posicionando al consumidor "en una situación de riesgo que, ante hechos o circunstancias imprevisibles e inesperados, le coloque en un estado de incapacidad generalizada para cumplir sus obligaciones"123.

A partir de las lógicas de los "préstamos responsables" es posible configurar una serie de reglas que pretenden, en términos globales, "que el prestamista asuma algún coste por comportamientos irregulares (y no meras multas administrativas impuestas por el regulador)"124. Estas no sólo se centrarán en un replanteamiento de sus efectos concursales por las malas prácticas de los concedentes del crédito, tales como la subordinación del crédito ${ }^{125}$, o la extinción de los saldos insolutos al término del procedimiento $^{126}$, sino que también precisan un despliegue en la dimensión

119 Sección 4.2.1 del Dictamen del Comité Económico y Social Europeo, de 12 de septiembre de 2014. Sobre la noción de "préstamo responsable", vid. Álvarez VegA, María Isabel, cit. (n. 27), pp. 397-410.

${ }^{120}$ Pulgar Esquerra, Juana, cit. (n. 12), p. 98.

${ }^{121}$ Sección 4.2.2 del Dictamen del Comité Económico y Social Europeo, de 12 de septiembre de 2014 .

122 Saint-Alary-Houin, Corinne, cit. (n. 9), p. 403.

${ }^{123}$ Colino Mediavilla, José Luis, Tratamiento de la crisis patrimonial del consumidor: ¿Procedimiento colectivo extrajudicial preconcursal, procedimiento colectivo preventivo, o procedimiento concursal especial?, en CuENA, Matilde - Colino, José Luis (coordinadores), Endeudamiento del consumidor e insolvencia familiar (Cizur Menor, Thomson Reuters / Civitas, 2009), p. 430.

${ }^{124}$ Cuena Casas, Matilde, cit. (n. 91), p. 32.

125 Cuena Casas, Matilde, cit. (n. 91), p. 32.

${ }^{126}$ JACKson, Thomas H., The logic and limits of bankrupty law (Cambridge / Londres, Harvard University Press, 2001), pp. 225 - 252, pero, p. 229. 
contractual del producto o servicio financiero. A mi juicio, una mirada exclusivamente concursal del fenómeno de la insolvencia inadvierte que existe una serie de medidas preventivas que pueden plantearse en la negociación entre los particulares, especialmente al confrontar al consumidor con un concedente profesional del crédito, sobre todo si este último se encuentra dotado de herramientas suficientes para aliviar los problemas conductuales y cognitivos de los tarjetahabientes, incluso antes que ellos se produzcan.

Entendido de este modo, la incorporación de un deber de asesoría o consejo en el contexto de los productos financieros se observa como el resultado de una suma de iniciativas desplegadas para evitar situaciones de sobreendeudamiento desde una perspectiva aún contractual (o, incluso, precontractual) del problema ${ }^{127}$. Así, en el contexto europeo, esto se manifiesta emparentado de forma parcial al deber de información contractual $^{128}$, y se dispone en el artículo 5.6 de la Directiva 2008/48/CE, de 23 de abril de 2008, relativa a los contratos de crédito al consumo, configurándose como un encuentro directo con el consumidor (bajo la lógica del denominado "meet your client") a fin de asistirle en la contratación. A partir del reconocimiento de un deber de este tipo en el contexto de las tarjetas de crédito podríamos suponer que el emisor logra identificar los riesgos a los que se expone el consumidor en virtud de las dificultades analizadas en el capítulo anterior y, en lugar de aprovecharse de ellos en lo que se refiere al diseño contractual del instrumento ${ }^{129}$, los comunica adecuadamente al tarjetahabiente en consideración a sus características particulares. Ello implica que el concedente del crédito debe constatar dichas particularidades y no contentarse con la caracterización estadística del sujeto y, conforme a aquellas, verificar la idoneidad del instrumento para la satisfacción de las necesidades reales del consumidor, y, en su caso, ofrecer términos y condiciones que se cohonesten con su situación financiera actual y proyectada.

Debe advertirse que la consagración de un deber de asesoría ${ }^{130}$ no

${ }^{127}$ Un amplio listado de las medidas que pueden considerarse para abordar el punto que, por supuesto, no se limitan a la incorporación de deberes de información y asesoría, puede encontrarse en la Sección 5.1 del Dictamen del Comité Económico y Social Europeo (2008/C44/19).

${ }^{128}$ Respecto a las diferencias entre uno y otro deber, vid. Hernández Paulsen, Gabriel, cit. (n. 29), pp. 128-129.

${ }^{129}$ BAR-GILL, Owen, cit. (n. 43), pp. 52-54.

${ }^{130}$ Para un desarrollo del contenido del deber de asesoría, debe tenerse presente la Directiva 2014/65/UE, de 15 de mayo de 2014, relativa a los mercados de instrumentos financieros (también conocida como "MiFID II"), el que describe la perso- 
constituye un elemento ignoto en nuestra legislación en el marco de los servicios y productos financieros. Al efecto, el artículo 529 N. 1 CCom (incorporado por la Ley N. ${ }^{\circ} 20.667$, de 2013) consagra una primera obligación precontractual por parte del asegurador de "prestar asesoría al asegurado, ofrecerle las coberturas más convenientes a sus necesidades e intereses, ilustrarlo sobre las condiciones del contrato y asistirlo durante toda la vigencia, modificación y renovación del contrato" ${ }^{131}$. Su justificación, como se advierte de la lectura de la historia de la citada ley, se encuentra en una forma de evitar ciertos abusos detectados en la industria en lo referente a la inadecuación del seguro a las necesidades del asegurado, que se encontraba desprovisto de apoyo técnico desde el momento de la contratación y toda la vigencia del contrato ${ }^{132}$. Así, el deber de asesoría se elabora como complemento del deber de información precontractual que pesa sobre la aseguradora ${ }^{133}$. En este sentido, no bastará con informar los aspectos fundamentales de la relación contractual, cuestión que ya se satisface con la propuesta (artículo 513, q] Ccom.), con la cotización (artículos 513, g] y 514 CCom) y con la debida integración de todas las normas pertinentes de la LPDC. (especialmente, el artículo 17B LPDC.). Lo anterior porque el deber de información aún se configura en los términos genéricos que requiere la contratación en masa, sin pretensión de asegurar la efectiva lectura y comprensión por parte de su destinatario ${ }^{134}$. En cambio, el deber de asesoría busca una particularización de dichos términos en la posición fáctica del consumidor, en términos de lograr una correcta adecuación de los términos informados a las necesidades reales de contratación y de los riesgos asumidos ${ }^{135}$. Conforme a ello, se debe

nalización de la información a ser entregada, poniendo especial énfasis en el ajuste a los niveles de tolerancia al riesgo y la capacidad para soportar pérdidas.

${ }^{131}$ La relevancia de esta norma es expresada por Barrientos Zamorano, Marcelo, Artículo 529: 1), en Ríos, Roberto (director) y ScHIELE, Carolina (editora), El contrato de seguro. Comentarios al Titulo VIII, Libro II del Código de Comercio (Santiago, Thomson Reuters La Ley, 2015), p. 335.

${ }^{132}$ Historia de la Ley N. ${ }^{\circ} 20.667$, p. 95. Pero la norma tampoco es nueva en nuestro ordenamiento, ya que en caso de que el seguro hubiese sido contratado con un intermediario, éste asumía un deber de asistencia en los términos de los artículos 57 y 58 del DFL N. ${ }^{\circ}$ 251, de 1931, particularizados por el artículo 10 del Decreto N. ${ }^{\circ} 1.055$, de 2013.

${ }^{133}$ Lo anterior se expresa con claridad en el Considerando 27 de la Directiva 2008/48/CE, de 23 de abril de 2008, relativa a los contratos de crédito al consumo.

${ }^{134}$ Barrientos Zamorano, Marcelo, Artículo 514, en Ríos, Roberto (director) y Schiele, Carolina (editora), El contrato de seguro. Comentarios al Titulo VIII, Libro II del Código de Comercio (Santiago, Thomson Reuters La Ley, 2015), p. 195.

135 En este sentido, la Corte de Apelaciones de Santiago, en sentencia de 26 de agosto de 2015 (rol 5959-2015), determinó la existencia de una infracción al deber de 
desplegar una conducta activa por parte del proveedor a fin de averiguar la situación del consumidor y determinar la conveniencia del producto para la satisfacción de sus intereses ${ }^{136}$, y, a partir de ello, dar lugar a un consejo que sirve a modo de guía más precisa (y menos neutra) que aquella que se logra por el mero acceso a la información. De ahí que el resultado de la infracción al deber de asistencia no sea reconducida a la nulidad del contrato de seguro ni a la posible modificación de su contenido (en los términos del artículo 17E LPDC.), dado que no se articula como un medio para enmarcar el contenido contractual (como sí ocurre en el deber de información), sino como fuente de responsabilidad por las "infracciones, errores y omisiones cometidos y de los perjuicios causados al asegurado", añadimos, con motivo de la falta de asesoría o de una asesoría insuficiente para el cumplimiento de su finalidad.

Ahora bien, en el campo de otros productos y servicios financieros, no parece posible efectuar sin más una aplicación analógica de la norma como esta se encuentra planteada en el CCom. No obstante, debe advertirse que esta clase de deberes logra adecuarse de mejor modo a los estándares de la corresponsabilidad antes mencionados, en particular si se considera que ellos se construyen desde la idea de que el proveedor debe participar activamente en la guía de la decisión de la contratación por parte del sujeto. Así, se ofrece un salto cualitativo desde el mero cumplimiento de mecánicas informativas formales (que se satisfacen por la entrega de ciertos datos considerados como relevante por el legislador o por el regulador) hacia la configuración de deberes fundados en la colaboración entre particulares. No debe olvidarse en este punto la consideración del contrato como expresión de la mentada cooperación, disponiendo a partir de ello ciertas cargas y deberes para las partes sobre la base de considerar, o, al menos, no ignorar abusivamente los intereses del otro. La ética contractual, nos señala Mazeaud, se manifiesta concretamente en las ideas de altruismo, decencia, coherencia, proporcionalidad y cooperación, excluyendo el egoísmo, la indiferencia, la ligereza y el cinismo ${ }^{137}$.

Conforme a lo anterior, creemos que este deber de asesoría puede

asesoría sustentada en el hecho de "no haber consultado acerca de las condiciones personales de los asegurados con el objeto de identificar sus necesidades e intereses de aseguramiento, ni haber entregado información esencial para la debida evaluación de parte de los aseguradores por la conveniencia de la oferta".

${ }^{136}$ Lo anterior se expresa con mayor claridad, por ejemplo, en la Circular N. ${ }^{\circ}$ 2180, impartida por la Superintendencia de Valores y Seguros el 25 de junio de 2015, respecto a la comercialización de seguros con cuenta única de inversión.

137 Mazeaud, Denis, Solidarisme contractuel et réalisation du contrat, en Grynbaum, Luc y NicoD, Marc, Le solidarisme contractuel (Paris, Economica, 2004), pp. 58-59. 
integrarse al contrato en virtud del principio de la buena $\mathrm{fe}^{138}$, considerando el carácter profesional del proveedor (y su consiguiente "deber de profesionalidad" afirmado en los arts. 1.2, 17B y 24 LPDC.) que permite efectuar una valoración de su conducta bajo los estándares de la lex artis ${ }^{139}$. Conforme a ello, el proveedor del producto financiero actúa bajo el conocimiento de la "legítima ignorancia" ser solucionada a partir de la sola entrega de la información, sino que debe ser complementada por un actuar diligente del profesional al tiempo de ofrecer una orientación integral respecto a la conveniencia, oportunidad y riesgos de la operación. Con ello, se cumple de mejor modo el principio de protección del consumidor que se desprende de una interpretación sistemática de nuestro ordenamiento ${ }^{141}$, como también del deber de no promover relaciones conflictivas ${ }^{142}$. A partir de lo anterior, cabe señalar lo siguiente: si en el contexto del marco normativo y negocial el proveedor del producto o servicio financiero debe ponderar los riesgos implícitos de la operación (por ejemplo, para la decisión de la contratación y de sus términos jurídicos y económicos particulares) ${ }^{143}$, no podría desconocerse que aquél, en razón de tal posición, puede ofrecer una asesoría profesional a la contraparte sobre los contornos y consecuencias económicas de la contratación, al mismo tiempo en que, si ha efectuado una valoración de los riesgos implícitos, pueda asimismo advertirlos al consumidor que, menos experimentado, podría no estar ponderándolos de manera adecuada. En el contexto del Derecho del consumo, intensificado por el desequilibrio entre las partes, ello implica constatar que el sobreendeudamiento es una vicisitud de la "sociedad de consumo", de modo que los riesgos también deben ser soportados por los acreedores que han permitido y promovi-

138 Chinchilla Imbetт, Carlos Alberto, El deber de información contractual y sus limites, en Revista de Derecho Privado, 21 (2011), p. 338.

139 Hernández Paulsen, Gabriel, La obligación precontractual de la entidad financiera de informar al cliente, especialmente a la luz de la Ley sobre protección de los derechos de los consumidores, en Estudios de Derecho Civil X (Santiago, Thomson Reuters, La Ley, 2014), pp. $351-373$.

140 Chinchilla ImbetT, Carlos Alberto, cit. (n. 130), p. 339.

141 Pinochet Olave, Ruperto, Modificación unilateral del contrato y pacto de autocontratación: dos especies de cláusulas abusivas a la luz del derecho de consumo chileno, en Ius et Praxis 19 (2011) 1, pp. 366-367.

142 Alvear Téllez, Julio, Consumidor y empresario: ¿relaciones jurídicas conflictivas? Hacia una concepción relacional del derecho del consumidor, en Revista Chilena de Derecho 43 (2016) 3, pp. 813-848.

143 De ahí que el análisis de la solvencia del consumidor se establezca como una obligación del proveedor en el contexto del artículo $8^{\circ}$ de la Directiva 2008/48/CE, de 23 de abril de 2008, relativa a los contratos de crédito al consumo. 
do el endeudamiento, incluso más allá de las facultades económicas del deudor ${ }^{144}$, o que, agregamos, estando en conocimiento de tales riesgos, no los comunica al consumidor para evitar el devenir de una situación patrimonial crítica.

Situados en el tema que nos convoca, queda por analizar la forma en la que este deber de asesoría se encuadraría en el marco de las tarjetas de crédito. No queremos decir con ello que sólo respecto a este instrumento el citado deber cobra relevancia, pero nos parece acertado señalar que, con motivo de las complejidades del producto, en éste puede apreciarse con mayor nitidez su necesidad. Al tiempo en que destacábamos los dos principales problemas relacionados con la adopción de decisiones de consumo y endeudamiento por el uso de las tarjetas, subrayábamos las dificultades que se presentaban para el deudor por las diferencias temporales entre la contratación, el uso y la decisión de pago, como aquéllas derivadas del usual optimismo del consumidor en la proyección de sus facultades económicas. Ambos aspectos pueden (y deben) ser identificados por el concedente del crédito dado su carácter profesional y por la necesaria ponderación de los riesgos conducentes a evitar problemas de selección adversa ${ }^{145}$ y para la determinación de los términos de la apertura de crédito subyacente (en particular, monto máximo y tasa de interés). Para ello, cuenta con la información que puede exigir al consumidor al tiempo de la contratación, como de aquélla que puede obtener de las fuentes públicas (por ejemplo, SBIF) y privadas (por ejemplo, a través de bureaus de crédito como DICOM); dispone de estadísticas generales del funcionamiento del mercado crediticio y de la situación económica del país y de sus habitantes ${ }^{146}$; y posee información específica derivada de la utilización de la tarjeta por parte del consumidor, como también de su comportamiento crediticio, la que debe expresar en la cartola (o estado de cuenta) que debe proporcionar al tarjetahabiente en los términos requeridos en el Decreto N. ${ }^{\circ}$ 44, de 2012.

Sobre la base de lo anterior, una interpretación normativa centrada en estándares de corresponsabilidad permite deducir ciertas conductas necesarias por parte del concedente del crédito para asistir al consumidor en su decisión de consumo, en términos generales, y de endeudamiento,

${ }^{144}$ Raymond, Gay, Solidarisme contractuel en droit de la consommation, en GrYnBAUM, Luc y NicoD, Marc, Le solidarisme contractuel (Paris, Economica, 2004), pp. 118-119.

${ }_{145}$ Celentani, Marco, El intercambio de información y el funcionamiento del mercado de crédito, en Prats, Lorenzo - Cuena, Matilde (coordinadores), Préstamo responsable y ficheros de solvencia (Cizur Menor, Thomson Reuters Aranzadi, 2014), p. 102.

${ }^{146}$ Sobre la relevancia de la evaluación de la solvencia e información crediticia, vid. Cuena Casas, Matilde, cit. (n. 91), pp. 62-75. 
en particular. Conforme a ello, si es posible advertir situaciones de riesgo de sobreendeudamiento, que, conocidas por el tarjetahabiente (sea al momento de la contratación, del uso o del pago), podrían guiar de mejor modo una decisión racional del sujeto, parece necesario que el concedente del crédito le comunique tal evaluación de manera pormenorizada a su situación particular. De este modo, privar de tal asistencia al consumidor puede terminar en un completo fracaso de las medidas preventivas al sobreendeudamiento, no sólo deteriorando la posición financiera del deudor, sino las propias expectativas de cobro de los emisores. De ahí en adelante ya deberán activarse formas resolutorias o curativas de una crisis patrimonial ya producida por medio de las reglas dispuestas en la Ley N. ${ }^{\circ}$ 20.720, de 2014, pero que, como todo instrumento concursal, pretenden funcionar a modo de recurso de ultima ratio ${ }^{147}$.

\section{Conclusiones}

Las tarjetas de crédito dan cuenta de un producto financiero extremadamente complejo, en especial, en lo referente a las destrezas que deben asumirse de parte del consumidor para la comprensión, no sólo de sus términos, sino de las consecuencias de su utilización en su economía personal. De este modo, el hecho de que el núcleo de la preocupación del ordenamiento jurídico nacional se haya centrado en la dotación de ingentes niveles de información sobre las características generales del instrumento, términos de uso y variables económicas no parece resolver ni los problemas de asimetría que aquejan al tarjetahabiente, ni toman en consideración las dificultades particulares de un dispositivo construido desde la separación entre los momentos de la celebración del contrato de emisión, de la decisión de utilización y de la deliberación de las alternativas de pago.

Conforme a lo anterior, una política de inclusión financiera basada en la expansión de esta clase de instrumentos puede derivar en situaciones en que la población termine sobreendeudada, cuestión que queda claramente evidenciada en los niveles de morosidad existentes en nuestro país. El sobreendeudamiento es un resultado previsible en la construcción de una "sociedad del consumo", por lo que el ordenamiento no puede ignorar que sólo la modulación de los estándares de racionalidad que soportan las reglas generales del Derecho de las obligaciones permite su

147 SAndoval López, Ricardo, Reorganización y liquidación de empresas y personas. Derecho concursal (Editorial Jurídica de Chile, Santiago, 2014), p. 22. Para un estudio comparado de las respuestas concursales a los problemas de insolvencia personal, vid. Ramsay, Iain, Personal insolvency in the 21st Century. A comparative analysis of the US and Europe (Hart, Oxford, 2017). 
reconsideración, constatando que nos situamos ante una relación que confronta al consumidor a un concedente profesional del crédito. Ello, sea porque el deudor no ha podido ponderar adecuadamente su propio riesgo de incumplimiento en atención a sus dificultades para la evaluación de su solvencia, sea porque no logra proyectar los efectos de su decisión de consumo (y, por tanto, de financiamiento) en situaciones trágicas que mermarán sus posibilidades de pago. Lo anterior no puede ser ignorado por el emisor de la tarjeta, precisamente porque su deber de profesionalidad, reconocido expresamente en el ámbito de la regulación de protección de los derechos de los consumidores, importa una evaluación de riesgos y la recolección de la información necesaria para poder llevar a cabo tal ponderación. De ahí que un otorgamiento irresponsable de crédito, en casos en los que pudieron preverse dificultades de pago, no justifica todos los extremos de la responsabilidad patrimonial, sustentada en la lógica habitual del Código Civil bajo la idea de la horizontalidad, y permiten incardinar, especialmente al amparo de la buena fe, deberes adicionales a los previstos expresamente por el legislador.

En este caso, he pretendido afirmar que, en atención a las dificultades antes reseñadas (en especial, aquellas que se refieren a la oportunidad de la información concedida al tarjetahabiente y a los sesgos optimistas), una protección adecuada del consumidor no puede detenerse en el cumplimiento de un deber de información estandarizado, propio de la contratación masiva, sin observar las complejidades propias del instrumento. Si el contrato por adhesión no puede ser interpretado bajo las lógicas de la voluntad común, sino a partir de parámetros objetivos derivados de la buena fe, el cumplimiento de deberes de información no puede justificar íntegramente la conservación del modelo clásico de responsabilidad previsto en la codificación decimonónica. De tal suerte, observando la intensificación del solidarismo contractual en los ámbitos del Derecho de consumo, podemos coincidir en la necesidad de elaborar un diseño normativo construido a partir de reglas que dispongan una colaboración más intensa entre las partes que permita un mejor cumplimiento de los fines del contrato.

Por ello, el resguardo de los consumidores de productos o servicios financieros sofisticados requiere ser complementado por una asesoría o consejo estructurado sobre los pilares del contacto efectivo entre el consumidor y el concedente del crédito. Lo anterior, que no se configura como un elemento extraño en la legislación nacional, permite generar un cierto estándar de responsabilidad del proveedor, en especial si se asumen las complejidades reconocidas de los términos operativos y financieros de las tarjetas de crédito y el deber de profesionalidad por parte del emisor, 
que tiene mejores herramientas para identificar el riesgo de sobreendeudamiento al que se expone el consumidor por el uso del instrumento. Con ello, se logra un primer avance en la configuración de un sistema más equilibrado, que logre superar la aparentemente encorsetada respuesta del Código Civil ante la insolvencia del deudor, y permite anclar el sistema en ciertas variables de corresponsabilidad y en la correcta distribución de los riesgos en quienes se encuentran en mejores condiciones para soportarlos.

\section{BiBLIOGRAFÍA}

ABIF, Informe N. ${ }^{\circ} 72$, de 28 de marzo de 2016 [visible en internet: www.abif.cl].

Aimone Gibson, Enrique, Protección de derechos del consumidor (Santiago, Legalpublishing Thomson Reuters, 2013).

Álvarez Vega, María Isabel, La protección jurídica del consumidor sobreendeudado e insolvente (Cizur Menor, Thomson Reuters Civitas, 2010).

Alvear Téllez, Julio, Consumidor y empresario: ¿ relaciones jurídicas conflictivas? Hacia una concepción relacional del derecho del consumidor, en Revista Chilena de Derecho 43 (2016) 3, pp. 813-848.

Anchával, Hugo, Insolvencia del consumidor (Buenos Aires, Astrea, 2011).

ANdRAde Ramírez, Víctor Miguel, La protección al consumidor de tarjetas de crédito: ¿son suficientes los deberes de información?, 2013 [visible en internet: https://papers.ssrn. $\mathrm{com} / \mathrm{sol} 3 /$ papers2.cfm?abstract id $=2349131]$.

Atamer, Yesim M., Duty of responsible lending: should the European Union take action?, en Financial services, financial crisis and general European contract law (Alphen aan den Rijn, Wolters Kluwer, 2011), pp. 179 - 201.

Ausubel, Lawrence M., The failure of competition in the credit card market, en The American Economic Review 81 (1991) 1, pp. 50-81.

Baquero Herrera, Mauricio - Caballero Germain, Guillermo, Artículo 17 G, en De La Maza, Íñigo - Pizarro, Carlos (directores) - Barrientos, Francisca (coordinadora), La protección de los derechos de los consumidores. Comentarios a la Ley de protección a los derechos de los consumidores (Santiago, Thomson Reuters, 2013), pp. 449 - 467.

Baraona González, Jorge, La nulidad de las cláusulas abusivas en la Ley N. ${ }^{0}$ 19.496: naturaleza y régimen, en BARRIENTOS CAMus, Francisca (coordinadora), Condiciones generales de la contratación y cláusulas abusivas (Santiago, Ediciones Universidad Diego Portales, Cuadernos de Análisis Jurídico, 2014), pp. 233-241.

BAR-GILL, Owen, Seduction by contract. Law, economics and psychology in consumer markets (Oxford, Oxford University Press, 2012).

Barrientos Zamorano, Marcelo (2013), Artículo $3^{\circ}$ B), en De la Maza, Íñigo - PiZARRO, Carlos (directores) - BARRIENTOS, Francisca (coordinadora), La protección de los derechos de los consumidores. Comentarios a la Ley de protección a los derechos de los consumidores (Santiago, Thomson Reuters, 2013), pp. 94 - 103.

Barrientos Zamorano, Marcelo, Artículo 529: 1), en Ríos, Roberto (director) SCHIELE, Carolina (editora), El contrato de seguro. Comentarios al Titulo VIII, Libro II del Código de Comercio (Santiago, Thomson Reuters La Ley, 2015), pp. 334 - 355.

Barrientos Zamorano, Marcelo, Artículo 514, en Ríos, Roberto (director) - Schiele, 
Carolina (editora), El contrato de seguro. Comentarios al Título VIII, Libro II del Código de Comercio (Santiago, Thomson Reuters La Ley, 2015), pp. 190 - 199.

Barros Bourie, Enrique, Tratado de responsabilidad extracontractual (Santiago, Editorial Jurídica de Chile, 2006).

Beltrán Sánchez, Emilio, El concurso de acreedores del consumidor, en Cuena, Matilde Colino, José Luis (coordinadores), Endeudamiento del consumidor e insolvencia familiar (Cizur Menor, Thomson Reuters Civitas, 2009), pp. 119-142.

Bouyon, Sylvain - MusCEMI, Roberto, Las dos dimensiones del sobreendeudamiento: protección del consumidor y estabilidad financiera en la Unión Europea, en La prevención del sobreendeudamiento privado. Hacia un préstamo y consumo responsables (Cizur Menor, Thomson Reuters Aranzadi, 2017), pp. 99 - 118.

Brito, Dagobert L. y HartLey, Peter R., Consumer rationality and credit cards, en Journal of Political Economy 103 (1995) 2, pp. 400 - 433.

Burton, Dawn, Credit and consumer society (Nueva York, Routledge, 2008).

CAPILla RONCERO, Francisco, La responsabilidad patrimonial universaly el fortalecimiento de la protección del crédito (Madrid, Ministerio para las Administración, 1989).

Carvajal Ramírez, Patricio-Ignacio, Tipicidad contractual y derecho de los consumidores. Artículo 16, letra g) de la Ley N. ${ }^{0}$ 19.496, en Elorriaga DE Bonis, Fabián (coordinador), Estudios de Derecho Civil VII (Santiago, AbeledoPerrot, LegalPublishing Chile, Thomson Reuters, 2012), pp. 441-448.

CELENTANi, Marco, El intercambio de información y el funcionamiento del mercado de crédito, en Prats, Lorenzo - Cuena, Matilde (coordinadores), Préstamo responsable y ficheros de solvencia (Cizur Menor, Thomson Reuters Aranzadi, 2014), pp. 93-115.

Chinchilla Imbett, Carlos Alberto, El deber de información contractual y sus límites, en Revista de Derecho Privado 21 (2011), pp. 327 - 350.

Colino Mediavilla, José Luis, Tratamiento de la crisis patrimonial del consumidor: ¿Procedimiento colectivo extrajudicial preconcursal, procedimiento colectivo preventivo, o procedimiento concursal especial?, en CuENA, Matilde - Colino, José Luis (coordinadores), Endeudamiento del consumidor e insolvencia familiar (Cizur Menor, Thomson Reuters / Civitas, 2009), pp. 429 - 457.

Cuena Casas, Matilde, El sobreendendamiento privado como causa de la crisis financiera y su necesario enfoque multidisciplinar, en PRATS, Lorenzo y CuENA, Matilde (coordinadores), Préstamo responsable y ficheros de solvencia (Cizur Menor, Thomson Reuters/ Aranzadi, 2014), pp. 27-89.

De la Maza Gazmuri, Íñigo, El suministro de información como técnica de protección de los consumidores: los deberes precontractuales de información, en Revista de Derecho (Universidad Católica del Norte), 17 (2010) 2, pp. 21 - 52.

De la Maza Gazmuri, Íñigo, Artículo $1^{\circ} \mathrm{N} .^{\circ} 3$, en de la Maza, Íñigo y Pizarro, Carlos (directores) y BARRIENTOS, Francisca (coordinadora), La protección de los derechos de los consumidores. Comentarios a la Ley de protección a los derechos de los consumidores (Santiago, Thomson Reuters, 2013), pp. 23 - 31.

De la Maza Gazmuri, Íñigo, Artículo 17 B (letras $A, B, C, D, E, F$ ), en De la Maza, Íñigo - PizArro, Carlos (directores) - BARrientos, Francisca (coordinadora), La protección de los derechos de los consumidores. Comentarios a la Ley de protección a los derechos de los consumidores (Santiago, Thomson Reuters, 2013), pp. 376-398.

Díez-PiCAzo, Luis, Fundamentos de Derecho civil patrimonial, Las relaciones obligatorias (sexta edición, Cizur Menor, Thomson Civitas, 2008) II.

Durkin, Thomas A. - Elliehausen, Gregory - Staten, Michael E. - Zywicki, Todd 
J., Consumer credit and the American economy (Nueva York, Oxford University Press, 2014).

Espada Mayorquín, Susana, Artículo $3^{\circ}$ F), en De la Maza, Íñigo - Pizarro, Carlos (directores) - BARRIENTOS, Francisca (coordinadora), La protección de los derechos de los consumidores. Comentarios a la Ley de protección a los derechos de los consumidores (Santiago, Thomson Reuters, 2013), pp. 133 - 139.

Eyal, Tal - Liberman, Nira - Trope, Yacov, Psychological distance and consumer behavior. A construal level theory perspective, en WänKe, Michaela (editora), Social psychology of consumer behavior (Nueva York - Londres, Psychology Press, 2009), pp. 65 - 87.

Fernández Acevedo, Fernando, Artículo $17 A$, en De la Maza, Íñigo - Pizarro, Carlos (directores) - BARRIEnTos, Francisca (coordinadora), La protección de los derechos de los consumidores. Comentarios a la Ley de protección a los derechos de los consumidores (Santiago, Thomson Reuters, 2013), pp. 364-375.

FRANK, Joshua M., Do credit card users systematically underestimate their interest rates? Evidence from the Survey of Consumer Finances, en Journal of Public Policy \& Marketing 30 (2011) 1 , pp. $133-139$.

Gete-Alonso y Calera, María del Carmen, Las tarjetas de crédito (Madrid, Marcial Pons, 1997).

Goldenberg Serrano, Juan Luis, Artículo 17 D, en De la Maza, Íñigo - Pizarro, Carlos (directores) - BARRIEntos, Francisca (coordinadora), La protección de los derechos de los consumidores. Comentarios a la Ley de protección a los derechos de los consumidores (Santiago, Thomson Reuters, 2013), pp. 419-439.

Goldenberg SERRANo, Juan Luis, La responsabilidad patrimonial universal y el sobreendeudamiento de la persona deudora, en Corral, Hernán - Manterola, Pablo (editores), Estudios de Derecho Civil XII (Santiago, Thomson Reuters, 2017), pp. 239-255.

Gomá Lanzón, Fernando, La supuesta complejidad de los llamados productos financieros complejos y la claridad como derecho del consumidor, en Prats, Lorenzo - Cuena, Matilde (coordinadores), Préstamo responsable y ficheros de solvencia (Cizur Menor, Thomson Reuters Aranzadi, 2014), pp. 181-206.

Guzmán Brito, Alejandro, El concepto de crédito en el Derecho chileno, en Revista de Derecho (Universidad Católica del Norte), 21 (2014) 2, pp. 429-452.

Helweg-Larsen, Marie y Shepperd, James A., Do moderators of the optimistic bias affect personal or target risk estimates? A review of the literature, en Personality and Social Psychology Review 5 (2001) 1, pp. 74-95.

Hernández Paulsen, Gabriel, La obligación precontractual de las entidades de crédito de informar al cliente en los servicios bancarios y de inversión (Madrid, Marcial Pons, 2014).

HeRnández Paulsen, Gabriel, La obligación precontractual de la entidad financiera de informar al cliente, especialmente a la luz de la Ley sobre protección de los derechos de los consumidores, en Estudios de Derecho CivilX (Santiago, Thomson Reuters, La Ley, 2014), pp. 351 - 373.

Hudon, Marek, Should Access to credit be a right, en Journal of Business Ethics 84 (2009), pp. $17-28$.

JACKSON, Thomas H., The logic and limits of bankruptcy law (Cambridge / Londres, Harvard University Press, 2001).

Massey, Cade - Simmons, Joseph P. - Armor, David A., Hope over experience: desirability and the persistence of optimism, en Psychological Science 22 (2011) 2, pp. 274-281.

MAZEAud, Denis, Solidarisme contractuel et réalisation du contrat, en GrYNBAUM, LUC - NICOD, Marc, Le solidarisme contractuel (Paris, Economica, 2004) pp. 57-71. 
Meier, Stephan - Sprenger, Charles, Present-biased preferences and credit card borrowing, en American Economic Journal: Applied Economies 2 (2010) 2, pp. 193 - 210.

Mella Cáceres, Rodrigo - Larraín Fierro, Álvaro, Derecho bancario (Santiago,Thomson Reuters La Ley, 2016).

Momberg Uribe, Rodrigo, El control de las cláusulas abusivas como instrumento de intervención judicial del contrato, en Revista de Derecho (Universidad Austral de Chile) 26 (2013) 1, pp. 9-27.

OECD, PIS A 2015 Results (Volume IV): Students' Financial Literacy (París, PISA, OECD Publishing, 2017).

Paterson, Jeannie Marie - BRODY, Gerard, "Safety net" consumerprotection: using probibitions on unfair and unconscionable conduct to respond to predatory business models, en Journal of Consumer Policy 38 (2015) 3, pp. 331-355.

Pérez Ragone, Álvaro - Martínez Benavides, Patricio, Del sobreendeudamiento a la insolvencia: fases de crisis del deudor desde el derecho comparado europeo, en Revista Chilena de Derecho 42 (2015) 1, pp. 93 - 121.

Pinochet Olave, Ruperto, Modificación unilateral del contrato y pacto de autocontratación: dos especies de cláusulas abusivas a la luz del derecho de consumo chileno, en Ius et Praxis 19 (2011) 1, pp. 365-378.

Prado Puga, Arturo, Algunas consideraciones sobre la tarjeta de crédito, en Gaceta Jurídica 131 (1991), pp. 7-16.

Pulgar Esquerra, Juana, El presupuesto objetivo de la prevención y tratamiento de las crisis económicas de los consumidores, en CuenA, Matilde y Colino, José Luis (coordinadores), Endeudamiento del consumidor e insolvencia familiar (Cizur Menor, Thomson Reuters Civitas, 2009), pp. 63-101.

Raga GiL, José T., Análisis socio-económico de la insolvencia familiar, en Cuena, Matilde Colino, José Luis (coordinadores), Endeudamiento del consumidor e insolvencia familiar (Cizur Menor, Thomson Reuters Civitas, 2009), pp. 27 - 59.

RAGA GIL, José T., Sobreendeudamiento privado y crisis financiera, en La prevención del sobreendeudamiento privado. Hacia un préstamo y consumo responsables (Cizur Menor, Thomson Reuters Aranzadi, 2017), pp. 43-97.

Ramsay, Iain, Consumer credit law, distributive justice and the welfare state, en Oxford Journal of Legal Studies 15 (1995), pp. 177 - 197.

Ramsay, Iain, Personal insolvency in the 21 st Century. A comparative analysis of the US and Europe (Oxford, Hart, 2017).

Raymond, Gay, Solidarisme contractuel en droit de la consommation, en GRYNBAUM, LuC y NicoD, Marc, Le solidarisme contractuel (Paris, Economica, 2004), pp. 117-124.

Rodríguez Grez, Pablo, Derecho del consumidor. Estudio crítico (Santiago, Thomson Reuters La Ley, 2015).

Rostión, Ignacio, SERN AC Financiero: nuevos deberes de información y responsabilidad civil, en Revista de Derecho (Universidad Católica del Norte) 21 (2014) 1, pp. 432 - 442.

Ruz LÁrtiga, Gonzalo, Nuevo Derecho concursal chileno (Santiago, Thomson Reuters, 2017), I.

SaInT-Alary-Houin, Corinne, El tratamiento de las dificultades financieras de los particulares en Francia, en Cuena, Matilde - Colino, José Luis (coordinadores), Endeudamiento del consumidor e insolvencia familiar (Cizur Menor, Thomson Reuters Civitas, 2009), pp. 401-415.

Sandoval López, Ricardo, Tarjeta de crédito bancaria (Santiago, Editorial Jurídica de Chile, 1991). 
Sandoval López, Ricardo, Derecho del consumidor (Santiago, Editorial Jurídica de Chile, 2004).

Sandoval López, Ricardo, Reorganización y liquidación de empresas y personas. Derecho concursal (Santiago, Editorial Jurídica de Chile, 2014).

San Martín Neira, Lilian, Artículo $3^{\circ}$ inciso $2^{\circ}$, en De la Maza, Íñigo - Pizarro, Carlos (directores) - BARRIENTos, Francisca (coordinadora), La protección de los derechos de los consumidores. Comentarios a la Ley de protección a los derechos de los consumidores (Santiago, Thomson Reuters, 2013), pp. 140 - 150.

SBIF, Informe de inclusión financiera en Chile 2016, 2016 [visible en internet: www.sbif.cl]. Sсотт, Robert H., III, Credit card use and abuse: a Veblenian analysis, en Journal of Economic Issues 41 (2007) 2, pp. 567 - 574.

SERNAC, Educación financiera en jóvenes: clave para un desarrollo económico saludable [visible en internet: http://www.sernac.cl/wp-content/uploads/2015/08/ Educaci $\% \mathrm{C} 3 \% \mathrm{~B} 3 \mathrm{n}$-financiera-en-j $\% \mathrm{C} 3 \% \mathrm{~B} 3$ venes -clave-para-un-desarrolloecon $\% \mathrm{C} 3 \% \mathrm{~B} 3$ mico-saludable-vf.pdf]

SwETT, José Tomás, Contratos de adhesión. Tarjeta de crédito bancarias (Santiago, Fundación Fernando Fueyo - Universidad Diego Portales, 2012).

Weinstein, Neil D., Optimistic biases and personal risk, en Science, 246 (1989) 4935, pp. 1232-1233.

White, Michelle, Bankruptcy reform and credit cards, en Journal of Economic Perspectives 21 (2007) 4, pp. $175-200$.

White, Alan M., Credit and human welfare: Lessons from microcredit in developing nations, en Washington and Lee Law Review 69 (2012) 2, pp. 1093-1140.

Wyer, Jr., Robert S. y Adaval, Rashmi, Social psychology and consumer psychology. An unexplored interface, en WäNKE, Michaela (editora), Social psychology of consumer behavior (Nueva York - Londres, Psychology Press, 2009), pp. 19 - 61. 